\title{
«ESTUDOS SOBRE AS MULHERES» EM PORTUGAL PÓS-DECLARAÇÃO DE PEQUIM - ESTUDO BIBLIOMÉTRICO DAS REVISTAS EX AEQUO E FACES DE EVA
}

\author{
Virginia Ferreira * \\ (D) https: / / orcid.org/0000-0003-3838-054X \\ Cristina C. Vieira* \\ (D) https: / / orcid.org / 0000-0002-9814-1076 \\ Maria João Silveirinha: \\ (D) https: / / orcid.org/0000-0002-0702-3366 \\ Elizângela Carvalho \\ (D) https: / / orcid.org/0000-0001-8341-2016 \\ Priscila Freire \\ (D) https: / / orcid.org/ 0000-0003-4031-543X
}

\section{Resumo}

Neste artigo fazemos a primeira apresentação e discussão de um conjunto de resultados parcelares do estudo bibliométrico das revistas ex æquo e Faces de Eva. A partir dos 259 textos da Faces de Eva e 399 da ex æquo, publicados entre 1999 e 2019, foi construída uma base Portugal; Presidente da direção da Associação Portuguesa de Estudos sobre as Mulheres (APEM); Diretora da ex æquo.

Endereço postal: Av. Dias da Silva, 165, 3004-512 Coimbra, Portugal.

Endereço eletrónico: virginia@fe.uc.pt

** $\quad$ Universidade de Coimbra, Faculdade de Psicologia e Ciências da Educação, 3001-802 Coimbra; Universidade do Algarve, CEAD-Centro de Investigação em Educação de Adultos e Intervenção Comunitária, 8005-139 Faro, Portugal; Vice-Presidente da direção da Associação Portuguesa de Estudos sobre as Mulheres (APEM); Editora Associada da ex æ⿱㇒⿻二丨䒑o.

Endereço postal: Rua do Colégio Novo, 3001-802 Coimbra, Portugal.

Endereço eletrónico: vieira@fpce.uc.pt

**** Universidade de Coimbra, Faculdade de Letras, 3004-530 Coimbra, Portugal; Membro da direção da Associação Portuguesa de Estudos sobre as Mulheres (APEM); Editora Associada da ex æq quo. Endereço postal: Faculdade de Letras, Largo da Porta Férrea, 3004-530 Coimbra, Portugal.

Endereço eletrónico: mjsilveirinha@gmail.com

*.:m* Doutoranda de Ciências da Comunicação da Faculdade de Letras, 3004-530 Coimbra, Universidade de Coimbra.

Endereço postal: Rua António José de Almeida, 86, 1E, 3000-041, Coimbra, Portugal.

Endereço eletrónico: elizc.noronha@gmail.com

****** Doutoranda de Sociologia da Faculdade de Economia da Universidade de Coimbra, 3004-512 Coimbra, Portugal; Escola Normal Superior da Universidade do Estado do Amazonas. CEP 69050-010 Manaus - AM. Brasil.

Endereço postal: Escola Normal Superior da Universidade do Estado do Amazonas. Av. Djalma Batista, 3578 - Flores - CEP 69050-010 Manaus-AM. Brasil.

Endereço eletrónico: pfrodrigues@uea.edu.br 
dos metadados constituída pelas características de autoras/es, e respetivas filiações institucionais e geográficas e pelos títulos, resumos e palavras-chave. Os resultados mostram que os Estudos sobre as Mulheres, de Género e Feministas (EMGF) têm vindo a consolidar-se como um campo de estudos interdisciplinares e com uma tendência crescente para a investigação de caráter colaborativo. Ao longo das duas décadas analisadas, é possível encontrar a emergência de diferentes temáticas e conceções, e uma diversidade nos perfis e regimes de autoria. A publicação destes resultados do estudo bibliométrico realizado procura facilitar a definição dos futuros possíveis e desenvolvimento do campo dos EMGF, num contexto de diálogo nacional e internacional.

Palvaras-chave: bibliometria, revistas ex æquo e Faces de Eva, Estudos sobre as Mulheres / de Género / Feministas, Portugal, 1999-2019.

\begin{abstract}
'Studies on women' in Portugal after the Beijing Declaration - bibliometric study of ex æequo and Faces de Eva journals

In this article we present and discuss a set of results of a bibliometric study of the journals ex æquo and Faces de Eva. The metadata of 259 texts of Faces de Eva and 399 of ex æquo's, published between 1999 and 2019, were incorporated into a framework basis which included authors, their institutional and geographical affiliations and as well as all the titles, abstracts and keywords. The results show that Women's, Gender and Feminist Studies (WGFS) consolidated as a field of interdisciplinary studies, with a growing trend towards collaborative research. Over the two analysed decades different themes and concepts, and a diversity of profiles and regimes of authorship emerged. The publication of this set of results of the undertaken bibliometric study aims to facilitate a better definition of the possible future and development of the WGFS field, in a context of national and international dialogue.
\end{abstract}

Keywords: bibliometrics, journals ex æquo and Faces de Eva, Women/Gender/Feminist studies, Portugal, 1999-2019.

\begin{abstract}
Resumen
'Estudios sobre mujeres' en Portugal después de la Declaración de Beijing - estudio bibliométrico de las revistas ex æquo y Faces de Eva

En este artículo hacemos la primera presentación y discusión de un conjunto de resultados parciales del estudio bibliométrico de las revistas ex æquo y Faces de Eva. A partir de los 259 textos de Faces de Eva y 399 del ex æquo, publicados entre 1999 y 2019, se construye una base de metadatos, constituida por las características de los autores y autoras y sus respectivas filiaciones institucionales y geográficas y por títulos, resúmenes y palabras clave. Los resultados muestran que los Estudios de las Mujeres/de Género/Feministas (EMGF) parecen haberse consolidado como un campo de estudios interdisciplinario, con una tendencia creciente hacia la investigación colaborativa. A lo largo de las dos décadas analizadas, es posible encontrar la emergencia de diferentes temáticas y conceptos, y una diversidad de perfiles y regímenes de autoría. La publicación de estos resultados del estudio bibliométrico realizado busca facilitar la definición del posible futuro y el desarrollo del campo de los EMGF, en un contexto de diálogo nacional e internacional.
\end{abstract}

Palabras clave: bibliometría, revistas ex æquo y Faces de Eva, Estudios sobre Mujeres / de Género / Feministas, Portugal, 1999-2019. 


\section{Introdução}

As revistas ex æquo - Revista da Associação Portuguesa de Estudos sobre as Mulheres e Faces de Eva - Estudos sobre a Mulher (ex æquo e Faces de Eva, daqui em diante) têm representado nas últimas duas décadas em Portugal um lócus singular de afirmação e desenvolvimento dos «Estudos sobre as Mulheres» no país. É possível através da análise dos seus conteúdos, acompanhar, de algum modo, as abordagens, temáticas e modos de produção de conhecimento que têm alcançado visibilidade especialmente em Portugal. Não exclusivamente dedicadas à produção nacional, têm veiculado a discussão e reflexão que nos chega de outros países que se fazem presentes pela autoria diversificada em diferentes línguas (português, inglês, espanhol e francês). A realização de um estudo bibliométrico de ambas as revistas não tem como objetivo comparar as revistas para daí extrair conclusões sobre a mais-valia de qualquer uma delas, mas antes obter uma panorâmica da produção das duas revistas que claramente se reclamam da área dos «Estudos sobre as Mulheres», dos «Estudos de Género» ou dos «Estudos Feministas» (EMGF, de ora em diante). O objetivo é fazer uma cartografia da produção científica ao longo de duas décadas, entre 1999 e 2019, nesta área de estudos e analisar os temas que nela ressaltam, portanto, os conhecimentos que são veiculados e o perfil de quem os trabalha. A finalidade do exercício que faremos é descritiva, e não avaliativa.

Trata-se, no entanto, de uma contribuição que procura ir além de uma análise de métricas dos artigos publicados, possibilitando uma abordagem sobre o aprofundamento dos EMGF no desenvolvimento de um olhar epistemológico sobre as temáticas nestes campos. Tendo ambas publicado o seu primeiro número em 1999, pensamos poder tomar a sua produção como indicador do desenvolvimento deste campo científico em Portugal, no pós-Declaração de Pequim (1995) que inaugurou oficialmente a era das políticas de mainstreaming de género.

A revista ex æquo é uma publicação internacional, fundada por um grupo de académicas de várias universidades, reunidas na Associação Portuguesa de Estudos sobre as Mulheres (APEM) $)^{1}$ e tem como objetivo a contribuição para o desenvolvimento, visibilidade e legitimação do conhecimento científico no âmbito dos EMGF. A revista Faces de Eva², por sua vez, foi criada por uma equipa de investigação da Faculdade de Ciências Sociais e Humanas da Universidade Nova de Lisboa e tem por objetivo divulgar ensaios e resultados de pesquisas na área, bem como dar visibilidade a mulheres e associações com contributos relevantes e pouco conhecidos.

A realização do presente estudo consistiu na construção específica de metadados com o objetivo de quantificar informações sobre ambas as revistas e, deste modo, identificar padrões e tendências em temáticas, estilos de autoria e contextos

https:/ / exaequo.apem-estudos.org/

https://www.fcsh.unl.pt/facesdeeva/ 
disciplinares e geográficos de produção. A metodologia utilizada está baseada na bibliometria e cientometria que inspiraram a forma de obtenção dos dados e sua sistematização para uma análise qualificada. Com efeito o objetivo da cientometria é gerar uma caracterização quantitativa da atividade científica e medir desse modo o progresso dos campos disciplinares, isto é, interpretar os dados quantitativos (Santos e Kobashi 2009; Hernández-Pozo e Fernández-Rius 2013; Feldman e Sandoval 2018; Aksnes, Langfeldt, e Wouters 2019).

O presente trabalho consiste, assim, na apresentação de ambas as revistas, desde o seu primeiro lançamento em 1999 até ao momento presente (ex æquo 1999-2019 e Faces de Eva 1999-2018). As métricas sistematizadas servirão para, numa perspectiva feminista, proceder a uma análise crítica e compreensiva da dinâmica histórica e cultural em que a área de «Estudos sobre as Mulheres» se tem vindo a desenvolver, sem esquecer que as opções investigativas dos/as autores/as e as suas oportunidades de publicação poderão ser influenciadas por fatores de natureza diversa.

A realização de estudos desta natureza confere a possibilidade de demonstrarmos os processos de afirmação de uma área científica e de produzirmos conhecimento reflexivo que oriente novos percursos de investigação. No âmbito dos «Estudos sobre as Mulheres», essa dimensão da análise lança o olhar ainda para o que é singular na sua produção científica, com reflexos na prática sociopolítica, a partir de um posicionamento feminista que busca mudanças sociais de prossecução de maior igualdade entre mulheres e homens. A história dos feminismos tem, em cada lugar, a sua feição de resistência, luta e esperança por tais conquistas, na qual a ex æquo e a Faces de Eva também deixam o seu registo.

Por fim, esperamos com esse trabalho contribuir para a produção científica, divulgação e o desenvolvimento das pesquisas em «Estudos sobre as Mulheres», «Estudos de Género»e «Estudos Feministas». ${ }^{3}$

\section{Trajetórias da produção científica nos EMGF em Portugal}

Em meados dos anos 1980, Ana Nunes de Almeida (1986) questionava-nos sobre a presença das mulheres como investigadoras e como «objetos» de investigação evidenciando que não havia uma relação direta enquanto tema de pesquisa em «Estudos sobre as Mulheres», apesar do crescimento da presença de mulheres no âmbito das Ciências Sociais. A partir dos anos de 1990, os «Estudos sobre as Mulheres» passam a representar a expressão de um campo científico em cresci-

Este trabalho é o resultado do projeto «Produção e divulgação do conhecimento científico promotor da igualdade social entre mulheres e homens: da Academia à sociedade», financiado pela Comissão para a Cidadania e Igualdade de Género, em 2019. A coordenação esteve a cargo de Virgínia Ferreira, com a colaboração de Cristina C. Vieira e Maria João Silveirinha. 
mento e de maior visibilidade. Consequentemente à denúncia do androcentrismo dominante na produção científica (e.g, Smith 1987; Reason 1994) claramente refletido nos conteúdos, linguagem e instituições académicas e educativas, os vários ramos das ciências sociais e humanas (pese embora as suas especificidades e diferenças de prestígio) têm produzido conhecimentos conscientes do modo como as relações sociais de género atravessam os seus saberes e referências disciplinares.

É neste quadro que cresceu o interesse pela temática em pesquisas no campo das Ciências Sociais e Humanidades e, com isso, passaram a existir programas de pós-graduação stricto sensu e foram lançadas as revistas especializadas ex æquo e Faces de Eva no mesmo ano de 1999 (Ferreira 2001; Joaquim 2004; Barroso, Nico e Rodrigues 2011; Amâncio e Oliveira 2014; Vieira et al. 2016). É possível afirmar, nesse sentido, que o interesse crescente nessa área emerge ao mesmo tempo em que a problematização da desigualdade entre mulheres e homens se faz notar no mundo laboral e académico como campos reflexos da realidade social contemporânea.

O impacto dos feminismos nos discursos científicos (Ferreira 2001), não mais como questionamento, aponta para a trajetória irrevogável de novos caminhos na medida em que os «Estudos sobre as Mulheres» fazem eco nas mais diversas áreas do saber científico. Em Portugal, a denominação dessa área, de acordo com Teresa Joaquim $(2004,89)$ está alinhada com o desenvolvimento das Ciências Sociais e com o feminismo no país. É no âmbito das Ciências Sociais que o conceito de género emerge entre ambivalências e tensões académicas (Amâncio e Oliveira 2014) de modo que os anos de 1990 são marcados, principalmente, pela discussão epistemológica do projeto feminista, não apenas no campo científico, mas também no político. A Sociologia, em especial, tem um contributo preponderante nesse debate em Portugal, uma vez que é a área de estudos com um significativo aumento de pesquisas e diversidade de produção científica consolidando um campo específico como «sociologia do género» nas décadas recentes (Rodrigues 2009; Barroso, Nico, e Rodrigues 2011).

Se, como vimos, os Estudos sobre as Mulheres, como formação académica institucionalizada, começaram com o reconhecimento da ausência das mulheres nos textos canónicos e na investigação em geral, seriam as revistas científicas, com revisão por pares, que viriam a oferecer o espaço para publicação de trabalhos neste domínio, cristalizando, sem deixar de alargar, o núcleo teórico do campo e aumentando a sua legitimidade. Assim, e acompanhando o processo histórico e político-cultural destes estudos em Portugal, as revistas ex æquo e Faces de Eva demonstram o processo de construção e consolidação desse campo científico ultrapassando as fronteiras nacionais ao estarem indexadas em bases bibliométricas internacionais, como a SCIELO e a LATINDEX, no caso de ambas as revistas, e na SCOPUS no caso da ex æquo. As revistas, separadamente, têm evidenciado ao longo das suas publicações tal processo (Ferreira 2001; Joaquim 2004; Ferreira 2013; Vieira et al. 2016), mostrando como os «Estudos sobre as Mulheres», os feminismos, as questões de género, significam na trajetória da produção portuguesa 
um campo ainda em expansão, mas incontestavelmente não ignorado, seja pelos crescentes contributos das suas pesquisas, seja pelo reconhecimento científico das publicações, ou ainda pela resistência contra a marginalização das perspectivas feministas e de género na academia.

\section{Os estudos bibliométricos e cientométricos e o campo dos EMGF}

Os estudos que visam analisar livros e revistas vinculados à gestão de bibliotecas e de bases de dados, chamados de bibliometria (Santos e Kobashi 2009), estão comummente aliados aos estudos de cientometria, ramo da sociologia das ciências e da ciência da informação, que consistem na análise da produção, circulação e utilização de conhecimentos científicos no âmbito de uma dada área científica, com o objetivo de gerar uma caracterização quantitativa e objetiva da sua dinâmica (Santos e Kobashi 2009; Hernández-Pozo e Fernández-Rius 2013). A ampliação dessas abordagens tem gerado uma discussão crítica sobre as metodologias usadas e as finalidades desses estudos. Como ilustrativo dessa questão, o Manifesto Leiden aponta para o risco de se projetar uma análise focada nos dados em vez de uma avaliação qualitativa do conhecimento na área científica estudada que garanta boas práticas e interpretação das informações geradas, além de enfaticamente criticar a predominância de métricas, dentre outros critérios centralizados na língua inglesa (Hicks et al. 2015).

Refletindo sobre a realidade americana, e usando métodos essencialmente qualitativos, uma das primeiras autoras a estudar publicações científicas feministas foi Patrice McDermott (1994), para quem

estas revistas oferecem uma área rica a ser investigada, já que se dirigem a práticas e processos de publicação académica, moldando simultaneamente os parâmetros de um corpo disponível de investigação feminista e contribuindo para o avanço da academia dos estudos sobre mulheres. Consequentemente, as revistas fornecem um modelo para a compreensão da mediação da resistência feminista e da autoridade patriarcal na produção do conhecimento cultural (p. 1).

Também pioneiro no campo dos Estudos sobre as Mulheres, mas com recurso ao método bibliométrico, foi o trabalho de Cronin, Martinson e Davenport (1997) que analisaram a distribuição de género em três revistas entre 1970 e 1994 (Feminist Studies, Signs: Journal of Women in Culture and Society e Frontiers: A Journal of Women's Studies). Estudaram, além disso, os agradecimentos (acknowledgements e acknowledgees), em termos do reconhecimento de comunicação peer-interactive (PIC), e do tom (afetivo ou factual) com que eram escritos. Em termos de autoria, verificaram que $90 \%$ dos artigos eram assinados por mulheres, não deixando de comentar que tal produzia «uma irónica inversão da crítica frequentemente feita pelas académi- 
cas feministas às disciplinas tradicionalmente dominadas pelos homens, como a química, a ciência da computação e a economia» (Cronin, Martinson e Davenport 1997). Estudaram ainda os membros editoriais das três revistas, constatando uma incompatibilidade com os objetivos publicamente declarados das revistas.

Desde então, vários estudos usaram indicadores bibliométricos, como o número de artigos, padrões de citação, práticas de colaboração e o índice-h (ver, nomeadamente, Abramo, D’ Angelo, \& Caprasecca, 2009; Borrego, Barrios, Villarroya, \& Ollé, 2009; Geraci, Balsis, \& Busch, 2015).

Registem-se em particular alguns trabalhos no domínio dos Estudos sobre as Mulheres. Dehdarirad, Villarroya, e Borrios (2015) investigaram o desenvolvimento e o crescimento da literatura científica sobre as mulheres na ciência e no ensino superior usando indicadores bibliométricos, procurando depois analisar a correlação entre o Índice nacional de desigualdade de género e o desempenho em pesquisa. Söderlund e Madison (2015) analisaram as publicações de estudos de mulheres de autoria sueca entre 2000 e 2010 e propuseram várias hipóteses sobre a sua taxa de crescimento, impacto e outros indicadores bibliométricos. Situando-se no campo da literatura sobre violência de género publicada entre 1982 e 2013, Brihante et al. (2016) recorreram também ao mesmo método para tipificarem a investigação nesse domínio. Refira-se ainda o trabalho de Tsay e Li (2017) que, também no campo dos estudos sobre as mulheres, mapearam bibliometricamente a investigação entre 1900 e 2013, mostrando que a literatura publicada em revistas de estudos neste campo cresceu exponencialmente, com uma taxa de crescimento anual de 10,6\% ao longo de mais de um século.

Por fim, e mais recentemente, Yun, Lee e Ahn (2020) analisaram mais de cinquenta e sete mil artigos de estudos sobre as mulheres publicados entre 1975 e 2017, explorando a estrutura intelectual do campo com base em palavras-chave extraídas das publicações e nas referências citadas. Entre os seus resultados, a partir da análise de referências citadas mais de 100 vezes, verifica-se que não só os estudos sobre as mulheres, mas também os estudos da psicologia social formam a base intelectual dos estudos de mulheres citados na literatura científica. Concluiram também que as publicações por volta da década de 1990, como Gender Trouble de Judith Butler, Black Feminist Thought de Patricia Hill Collins e In a Different Voice de Carol Gilligan formaram um importante fundo de conhecimento para a área.

Santos e Kobashi (2009, 159) ressaltam que a atividade científica não se resume aos dados produzidos e muito menos se confunde com o que é o desenvolvimento do conhecimento cognitivo da ciência. Tais questões são pertinentes na nossa abordagem, uma vez que apresentamos uma produção científica dos «Estudos sobre as Mulheres» em duas revistas publicadas predominantemente em língua portuguesa nas últimas duas décadas. Inserida no panorama internacional atual da discussão e produção sobre essas temáticas, a produção do conhecimento científico dos EMGF apreende tal dimensão sem com isso perder de vista uma problemática epistemológica crítica a partir dos seus contextos. 
Como um campo profícuo para a análise da produção científica dos «Estudos sobre as Mulheres», a bibliometria e a cientometria possibilitam-nos uma abordagem que agrega ao aspecto quantitativo de autores, artigos, etc., uma análise cada vez mais aprofundada desde a perspectiva sociológica (Santos e Kobashi 2009). Assim, além de apreendermos as dimensões políticas e sociais da comunidade científica em torno dos EMGF (Hernández-Pozo e Fernández-Rius 2013), podemos percecionar a relevância para o tema no modo como a seleção de referências vai sendo feita nessa área de estudos (Aksnes, Langfeldt e Wouters 2019), entre outras considerações da análise.

\section{Corpus documental e análise dos dados}

Os resultados que apresentamos a seguir consistem na sistematização de um conjunto de 41 metadados (ver anexo) das revistas ex æquo e Faces de Eva referentes aos seus 20 anos de publicação, com a utilização do software de análise SPSS (Versão 22) e do Excel. ${ }^{4}$ Estes 41 metadados permitem-nos conhecer melhor a atividade de edição das revistas nas seguintes vertentes:

- perfis de quem nelas publicou, incluindo as áreas científicas e instituições de filiação;

- prevalência de temáticas e metodologias;

- prevalência e padrões de colaboração entre áreas disciplinares, institucionais e geográficas;

- padrões de referenciação bibliográfica (origens e suportes = países e tipo de publicações $=$ artigos, livros, atas, relatórios, etc.).

Nesta apresentação de resultados, analisamos algumas das informações das revistas em conjunto e outras em separado, pois a diferença de estrutura torna, em alguns momentos, inadequada uma análise comparativa entre ambas. Dessa forma, optamos por eventuais aproximações a fim de reconhecer os contributos em conjunto, respeitando as singularidades que apresentam e estão expressas nos seus modos particulares de apresentação e contextos institucionais em que se têm desenvolvido ao longo das últimas duas décadas.

Da ex æquo foram analisadas 39 edições, compreendendo o período de 1999 a 2019, e 399 artigos científicos publicados em dossiês temáticos e na secção «Estudos e Ensaios». Nestes 20 anos de publicação sistemática, a ex æquo tem mantido uma média regular de textos, cerca de 20 por ano, salvo no ano de 2002, quando a sétima edição - dedicada ao tema «Reformular os debates educacionais sobre a cidadania,

A Faces de Eva realizou um estudo bibliométrico cujos resultados foram publicados e analisados em Vieira et al. (2013). Nesse estudo foram analisadas todas as secções da revista: Estudos; Entrevistas; Pioneiras; (Auto)-retrato; Toponímia. Para o estudo de que aqui damos conta foi construída uma base de dados própria, que apenas se centrou na secção Estudos. 
agência e identidade das mulheres» - trouxe 18 trabalhos que, somados à sexta edição, publicada no mesmo ano, perfaz 29 artigos.

Já na Faces de Eva, o corpus trabalhado contempla 40 edições, no período de 1999 a 2018, com o total de 259 artigos e ensaios publicados nas secções «Estudos» e «Estado da Questão». As edições de Faces de Eva apresentam uma média mais regular, embora em menor número, de trabalhos por ano de publicação.

\section{Línguas usadas nas publicações}

A partir dos dados obtidos através das análises das revistas, verificamos a predominância da Língua Portuguesa como idioma dos artigos (ver gráfico 1).

\section{Gráfico 1.}

Idiomas publicados, 1999-2019

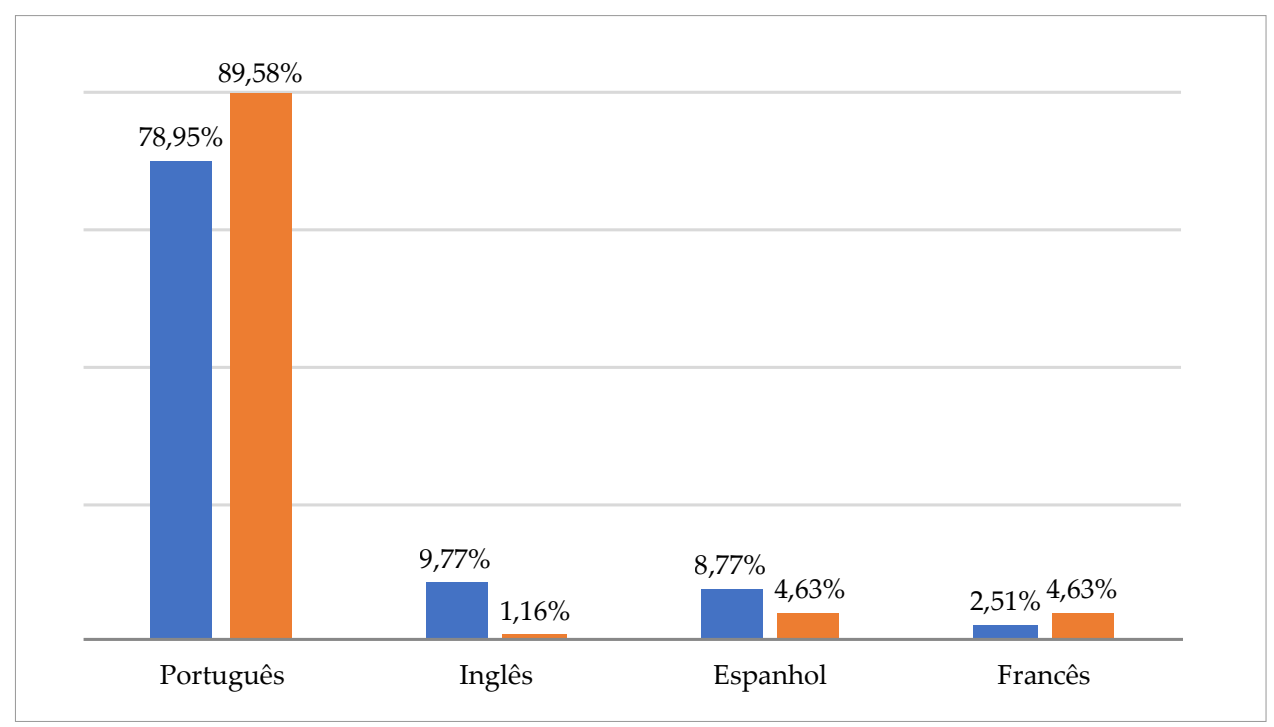

Observamos, no entanto, que as revistas se mantêm abertas a autoria proveniente de múltiplas nacionalidades e aceitação de textos em outros três idiomas, a saber: inglês, espanhol e francês. Essa pluralidade de idiomas está plasmada na publicação de trabalhos na língua de origem, já que apenas uma pequena parcela dos trabalhos é proveniente de traduções (5\% no caso da ex æquo e 2\% na Faces de Eva). Apenas autoras/es de renome internacional em EMGF têm originais traduzidos, ampliando o acesso a referências teóricas fundamentais nessa área. A desagregação por períodos de cinco anos mostra uma crescente inclusão de textos em outras línguas, em especial o Espanhol e o Inglês. 


\section{Autoria - Contextos institucionais e geográficos}

A observada predominância da Língua Portuguesa justifica-se pela presença maioritária de autoras/es filiadas/os em instituições sediadas em Portugal. O Brasil e os países africanos somam-se a Portugal nesta matéria. Como podemos verificar (ver gráfico 2) há, nas revistas, uma significativa diversidade de origens institucionais de diferentes geografias.

\section{Gráfico 2.}

País da Instituição da/o 1. ${ }^{\circ}$ Autor/a, 1999-2019

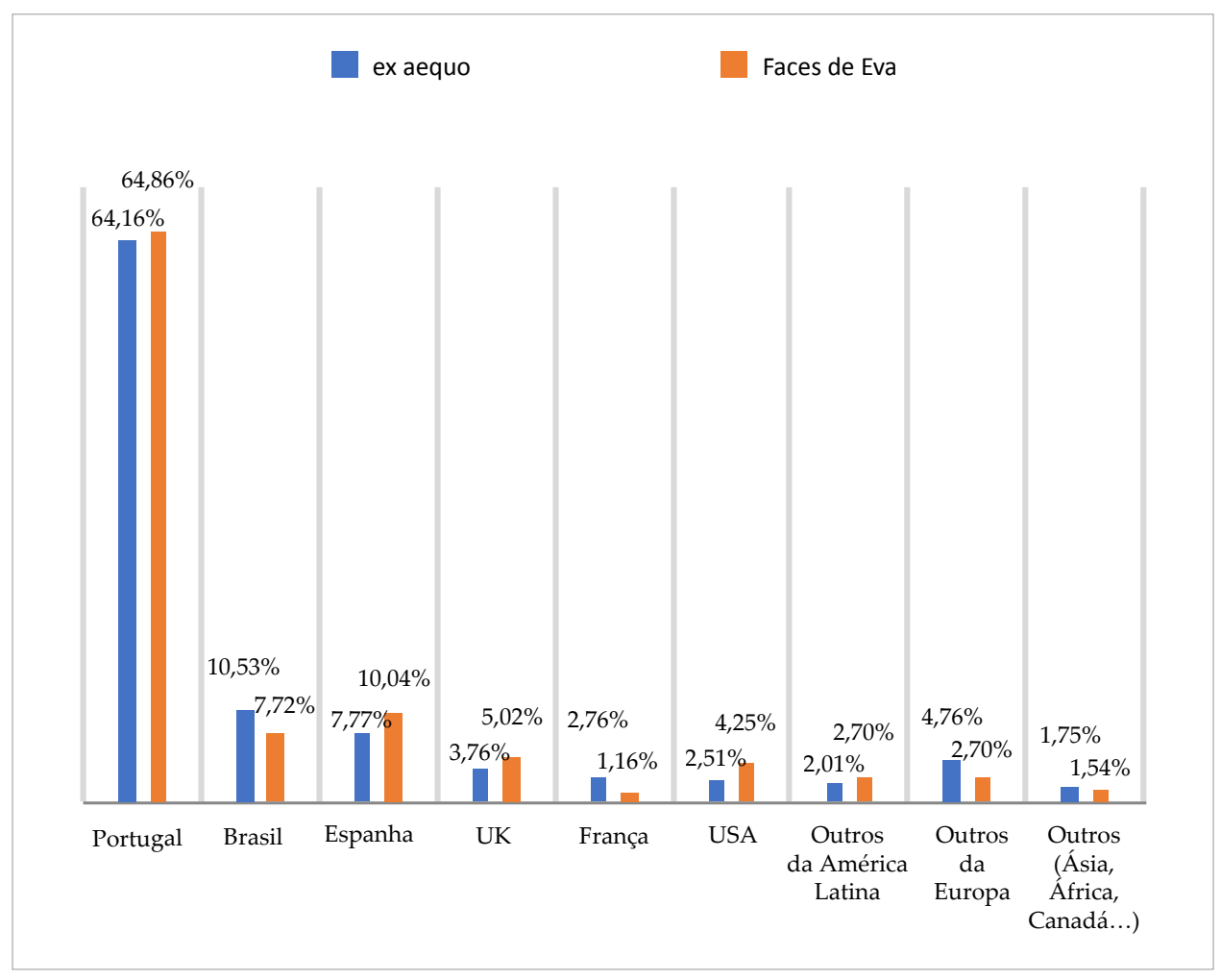

Em ambas as revistas há a clara predominância de autoras/es ligadas/os a instituições de ensino superior (ver gráficos $3 e$ 4), sendo na sua esmagadora maioria investigadoras a assinar os textos, o que reforça o reconhecimento das contribuições de mulheres na produção teórica e, por consequência, no contributo efetivo para o aprofundamento epistemológico nos EMGF no seio da academia. Com efeito, a quase totalidade dos textos publicados nas duas revistas provém do trabalho nas universidades: 86,7\%, no caso de ex æquo; 71,4\%, no caso da Faces de Eva. 
Gráfico 3.

ex æquo: Filiação institucional de 1. ${ }^{\circ}$ Autor/a, por sexo (1999-2019)

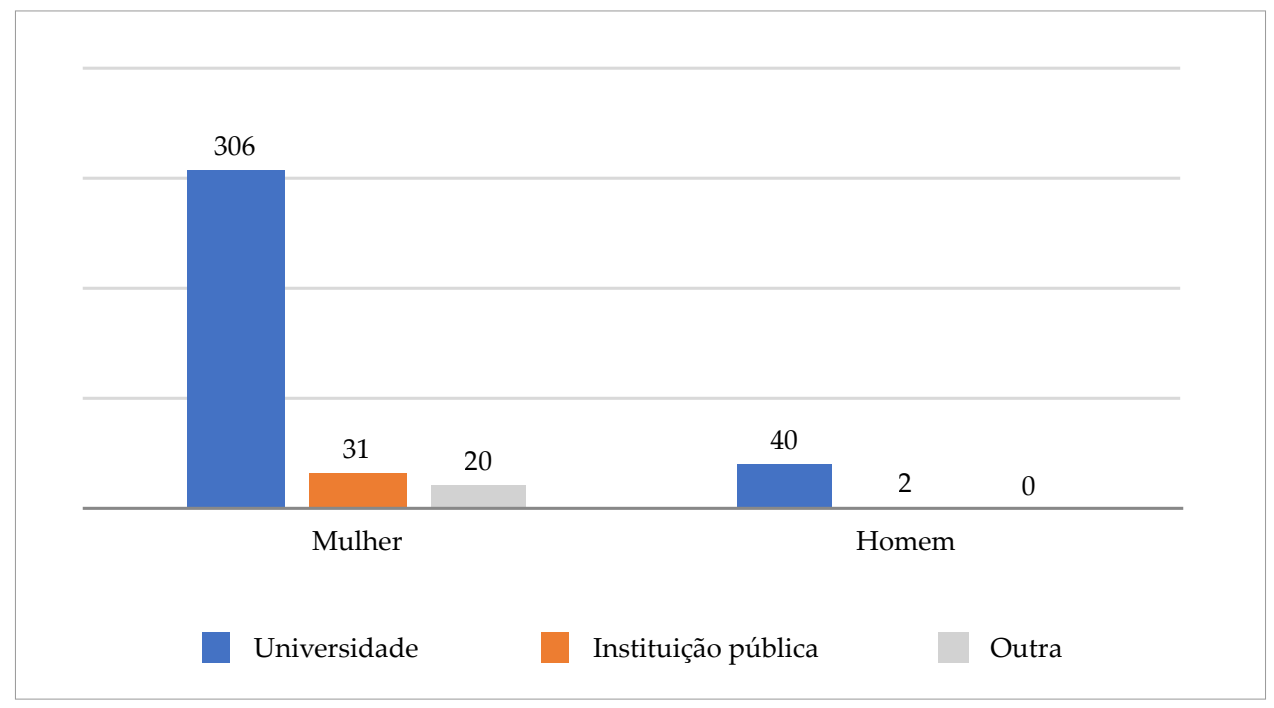

Gráfico 4.

Faces de Eva: Filiação institucional de 1. ${ }^{\circ}$ Autor/a, por sexo (1999-2019)

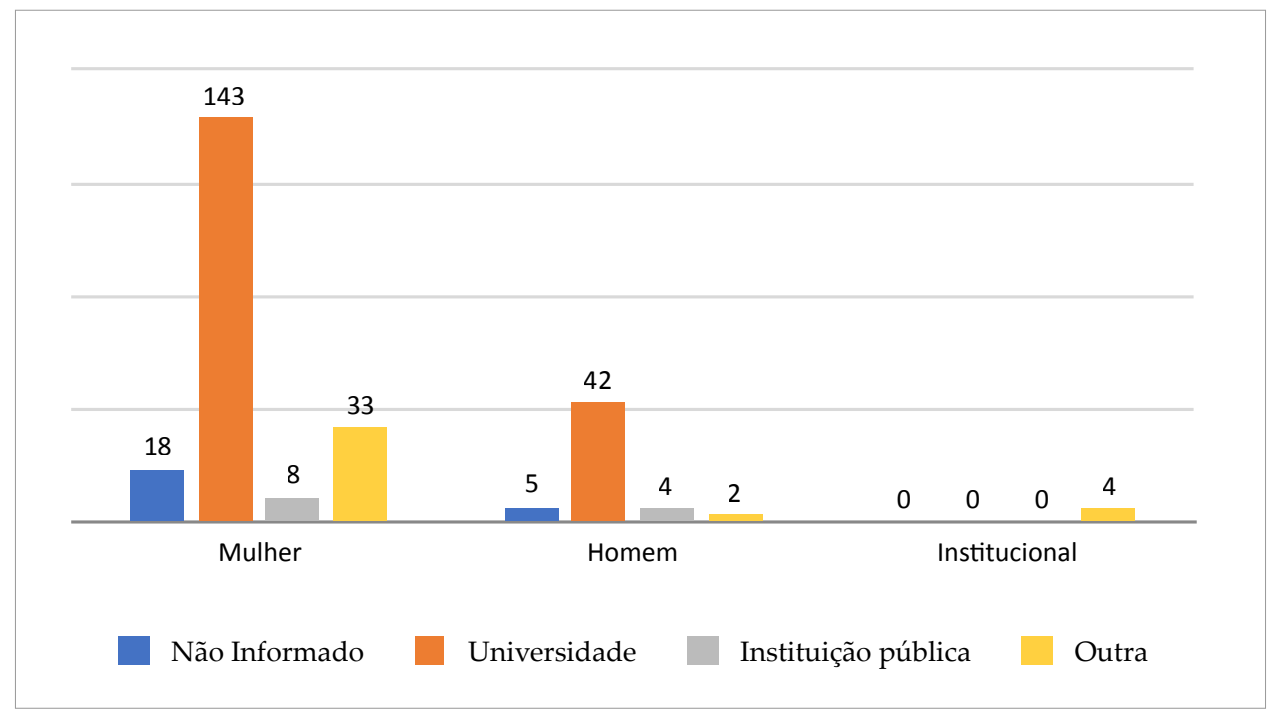

Dado que a revista Faces de Eva tem como particularidade a publicação da rubrica «Estado da Questão» - dedicada a apresentar «movimentos e organizações feministas, de apoio às mulheres, com grande participação feminina» (Vieira et al. 
2016, 40) - registamos a presença de assinatura institucional, o que mostra a valorização da representação coletiva dessas instituições (ver gráfico 4). Esta revista tem, portanto, um perfil menos estritamente académico.

As instituições de filiação também são diversas na sua área de atuação, já que a maior parte delas (ver gráfico 3) cobre diferentes domínios de pesquisa, demonstrando a abertura das revistas a instituições e investigadoras/es para além de centros e associações especializadas em EMGF. Ainda assim, as instituições especializadas correspondem a percentagens importantes na produção/divulgação de conhecimento científico nessa área. Ressalta, portanto, à vista que o propósito de mainstreaming de género tem alimentado as publicações, promovendo:

O diálogo com outras áreas também elas ainda emergentes, constitui um desafio para as áreas disciplinares e científicas constituídas, pela inovação dos temas e das abordagens, pelo risco de transgressão das fronteiras disciplinares, pelos novos estilos de escrita, pela própria emergência e articulação com outros pontos de partida» (Joaquim 2004, 92).

O facto de, no caso da ex æquo, quase metade dos artigos ter como primeira/o autor/a alguém com filiação numa instituição com investigação na área dos EMGF revela a crescente institucionalização desta área de estudos. Esta informação não deixa, contudo, de ser ambígua, porque esta filiação institucional pode não excluir a inscrição disciplinar dos/as autores/as nas disciplinas mais convencionais, como se pode constatar mais à frente (gráficos 14 e 15).

\section{Gráfico 5.}

Filiação em instituições com especialização em EMGF da/o $1^{\circ}$ autor/a, 1999-2019

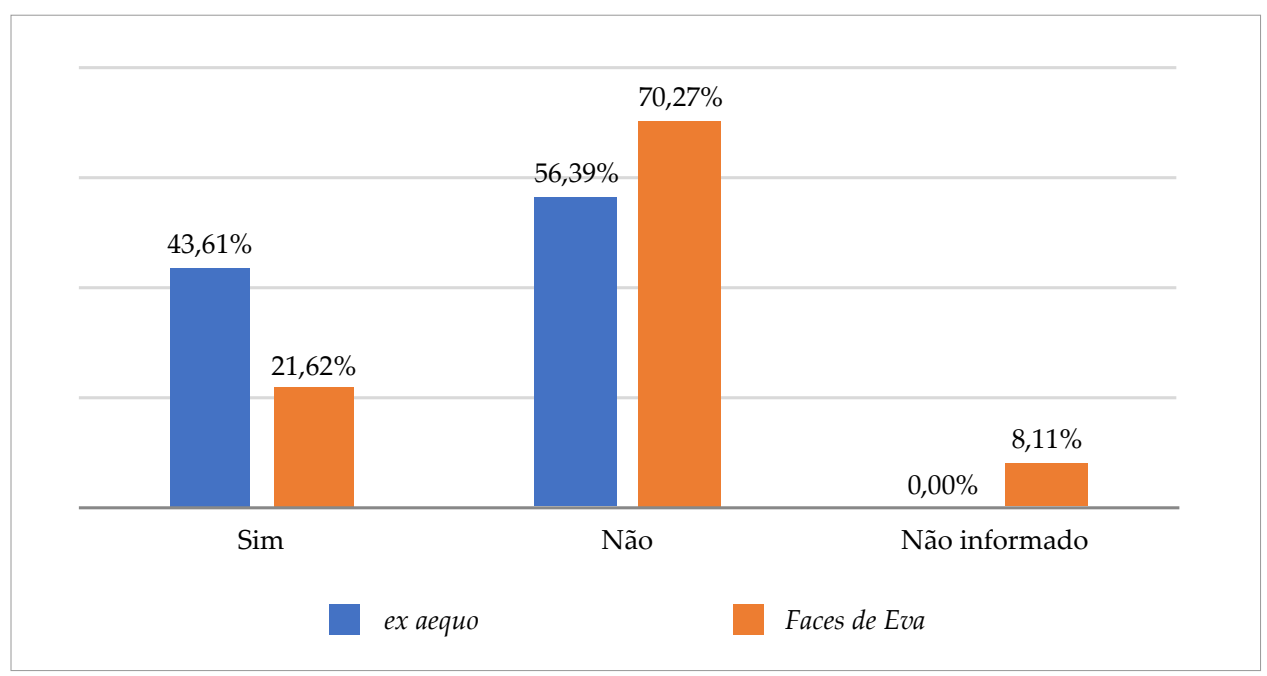


De notar que, enquanto parte do sistema de comunicação académica, o processo de publicação combina os elementos de recompensa, responsabilidade e reconhecimento (Cronin 1984; Henriksen 2016). A autoria é, neste processo, um elo essencial, já que é por ela que a/o investigador/a faz reivindicações de conhecimento, procurando, nomeadamente, demonstrar a originalidade e o valor do seu trabalho, responsabilizando-se por ele e procurando o reconhecimento dos seus pares.

Como seria de esperar, e como já se mencionou atrás, a maior parte dos textos em ambas as revista tem autoria feminina. A colaboração de autores tem-se verificado nestes 20 anos das publicações, com contributos especialmente no tema das sexualidades, temática em que os textos são assinados maioritariamente por homens.

\section{Fontes de inspiração mobilizadas}

A produção dos artigos demonstra uma diversidade de fontes bibliográficas nas duas revistas. Muitos trabalhos utilizam documentos históricos, notícias de imprensa, relatórios de organizações nacionais e internacionais, legislação, entre outros, como fontes relevantes para os respetivos estudos. Observamos ainda que, nos trabalhos com ampla consulta documental, a fundamentação teórica está baseada em livros, - verificando-se uma percentagem equivalente $(55 \%)$ em ambas as revistas (ver gráfico 9). Por outro lado, o peso dos artigos entre as fontes citadas ( $28 \%$ na ex æquo e $21 \%$ na Faces de Eva) indicia a preocupação de se consultarem fontes publicadas em revistas diversas, no sentido de uma busca de informação cada vez mais atualizada.

\section{Gráfico 6.}

Tipologia das referências bibliográficas por revista

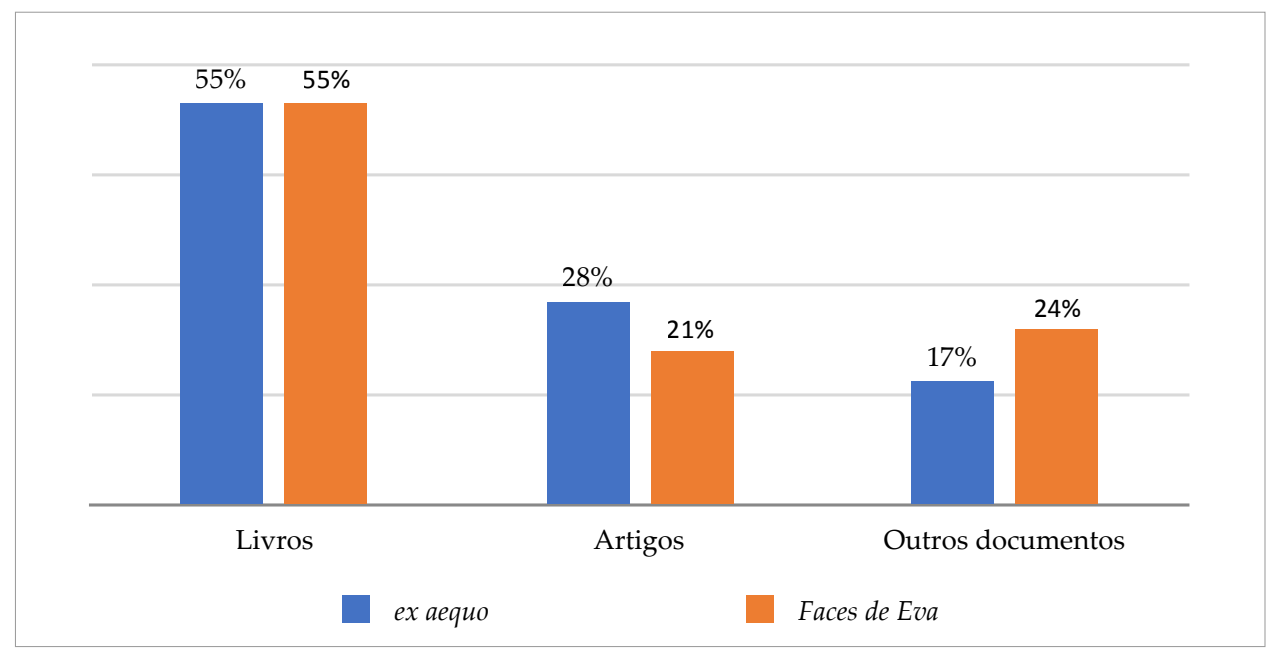


Tal reflete-se na média crescente de referências bibliográficas por artigo (ver gráfico 7). Ao observar os intervalos de cinco anos de publicação da ex æquo verificamos que no período de 1999 a 2004 a média era de 20,65 referências por artigo. Já nos últimos cinco anos, essa média subiu para 31,72. Na Faces de Eva, também se observa um acentuado crescimento do número de referências bibliográficas ao longo da década de 2010. ${ }^{5}$ No período 2015-2019, contabilizámos uma média de 22,5 referências bibliográficas por artigo.

\section{Gráfico 7.}

ex æquo - Número médio de referências bibliográficas por artigo, por quinquénio

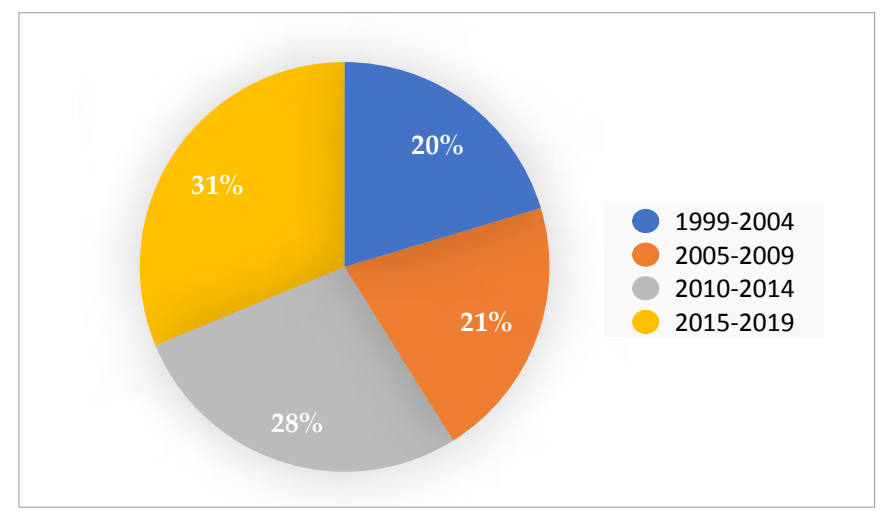

Sobre a frequência dos países de onde provêm os contributos teóricos e empíricos citados, verificamos que, na ex æquo, predominam referências a publicações de mesma nacionalidade da/o autor/a. Portugal é o país com maior presença nas citações, sendo preponderante em 147 dos 399 artigos analisados (ver gráfico 8). É importante observar ainda a forte presença de literatura de língua inglesa nas edições, pois identificamos 94 trabalhos em que as referências publicadas no Reino Unido ou Estados Unidos foram mais recorrentes.

5 No caso das publicações de Faces de Eva só foi possível fazer esta aferição, a partir do n. ${ }^{\circ}$ 32, devido a duas características da revista: 1) Em muitas edições, a revista adotava como norma a disposição das referências bibliográficas em notas de rodapé. Essa formatação impossibilitou a identificação fidedigna entre: obras citadas, indicações de leituras, comentários com novas referências, além da eventual repetição de uma mesma referência; 2) Em alguns artigos havia a indicação "para consultar bibliografia: www.fcshunl.pt/facesdeeva», no entanto, o link não esteve disponível para consulta durante o período de colheita e tratamento da informação. As referências aparecem de maneira normatizada na Faces de Eva somente a partir da edição 32 da revista, portanto, os dados recolhidos acerca dessa variável só nos permitem obter a média por artigo nos dois últimos quinquénios. 
Gráfico 8.

ex aequo - Países preponderantes nas referências bibliográficas

\section{Número de artigos}

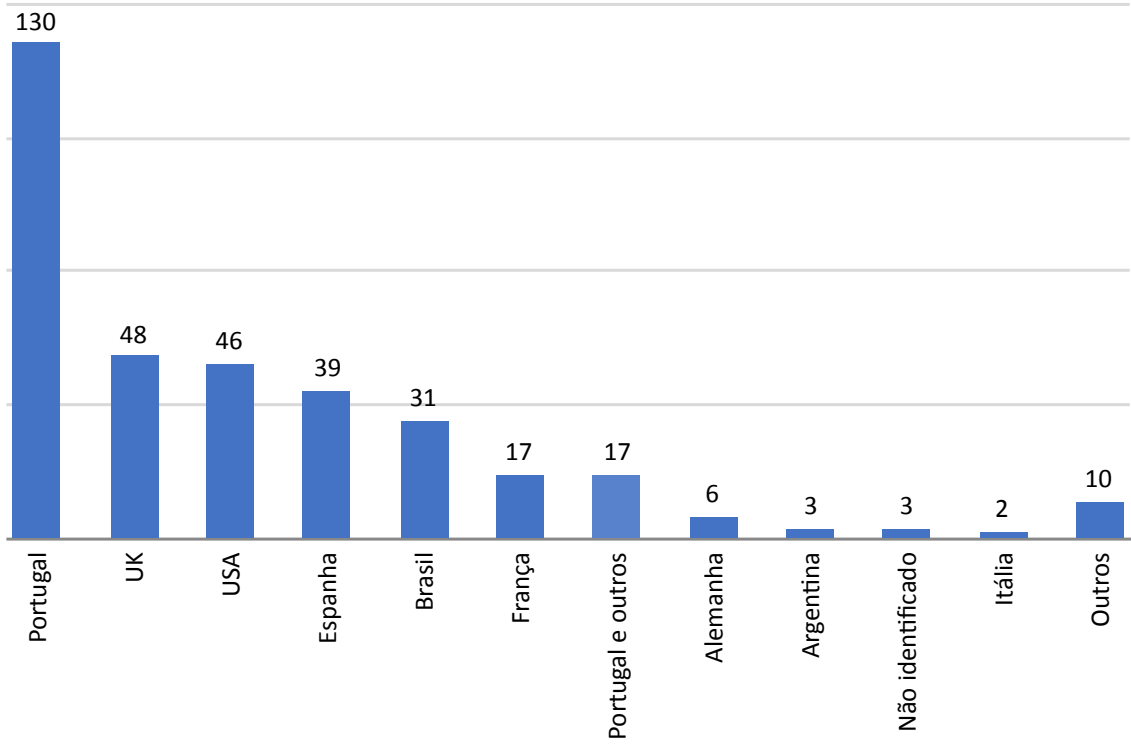

As estratégias de citação têm sido objeto de estudo, desde que Derek John de Solla Price, a partir do Institue for Scientific Information (ISI), começou, nos anos 70 do século passado, a analisar as relações estruturais das redes de referências e de citações (Santos e Kobashi 2009). ${ }^{6}$ Dos indicadores apurados relativamente às citações, queremos sublinhar o facto de a maior parte das fontes bibliográficas coincidirem na origem com os países das/os autoras/es. Esta é uma marca distintiva da ex æquo que mostra a relevância da sua missão - dar visibilidade aos EMGF em Portugal. É, por outro lado, interessante que não se verifique a tendência, observada em outros países periféricos ao sistema científico internacional, de as citações se centrarem em especial em publicações dos países centrais desse sistema, pelo

Esta análise partiu do Science Citation Index (SCI), criado por Eugene Garfield em 1961 (Aksnes et al. 2019, 2). Originalmente, esta base de dados bibliográfica foi construída principalmente para fins de recuperação de informações, para auxiliar na identificação de artigos relevantes nos enormes arquivos de literatura científica. Como subproduto, passou a ser usado para analisar quantitativamente a literatura científica. Desde a década de 1960, o SCI e outras bases de dados similares, agora incluídas online no Web of Science. Nesta base de dados, estão registadas as referências dos artigos indexados. Com base nisso, a cada artigo pode ser atribuído uma contagem de citações mostrando quantas vezes foi citado por artigos posteriores constantes na base de dados. 
facto de só estas serem consideradas fontes prestigiadas de conhecimento (Hoppen e Vanz 2020).

Esta prevalência de referências bibliográficas nacionais tem um reverso na escassa atenção dada às publicações das duas revistas, subsequentemente à desconsideração que o centro produtor de conhecimento dedica aos conhecimentos produzidos na periferia. Assim, a ex æquo contabiliza 151 citações no portal da SCIELO, no período 2008-2020 (11,6 em média por ano) e a Faces de Eva 20, contabilizadas no período 2014-2020 no mesmo portal (2,85 de média anual). ${ }^{7}$ Uma das razões para esta falta de reconhecimento prender-se-á, em parte, com o facto de o centro se expressar e ler essencialmente na língua inglesa. Esta consciência é cada vez mais determinante da opção pela publicação em língua inglesa, mais recorrente em ambas as revistas, ${ }^{8}$ mesmo quando os textos são de autoria nacional, o que não será um argumento suficiente para que o centro se interesse pelas problemáticas trabalhadas na periferia. O vaticínio feito por Caren Kaplan, por altura da criação das duas revistas, de que a receção do conhecimento tinha que seguir orientação diferente da lógica preponderante, isto é, «from the West to the rest», continua por concretizar (Kaplan 1994 apud Pesole 2012, § 62).

Assim como a nacionalidade da autoria se refletiu nos países das referências, verificamos relação semelhante entre a localização dos objetos de estudo e o país de filiação da/o primeiro/a autor/a. Portugal é objeto de estudo em $43 \%$ dos artigos publicados na ex æquo (ver gráfico 9) e em $54 \%$ na Faces de Eva (ver gráfico 10). É importante destacar a quantidade de trabalhos de reflexão teórica em ambas as revistas (22\% na ex æquo e 15\% na Faces de Eva), ou seja, sem a análise de um objeto empírico específico. Entendemos esse dado como reflexo da crescente preocupação epistemológica dos EMGF nas últimas décadas.

A observação situada dos/as autores/as, no entanto, não limita o campo de análise, uma vez que há vários estudos comparativos em ambas as revistas entre diferentes países (8\% ex æquo e $6 \%$ na Faces de Eva), tendo ainda a comparação com Portugal (43\% ex æquo e $54 \%$ na Faces de Eva) a maior incidência.

$7 \quad$ No caso da ex æquo, 50\% são autocitações, percentagem que aumenta para 75\%, no caso da Faces de Eva (respetivamente em http://statbiblio.scielo.org//stat biblio/index.php?no=09.xml\& state=09\&lang=pt\&issn=0874-5560 e http:/ / www.scielo.mec.pt/statjournal.php?lang=pt\&issn $=0874-6885 \&$ collection $=$ prt, consultadas no dia 1 de dezembro de 2020 .

$8 \quad$ Na ex æquo a abertura à publicação em inglês, francês e espanhol ocorreu em 2005 (Pinto 2009, 67). 


\section{Gráfico 9.}

ex æquo - Países mais pesquisados

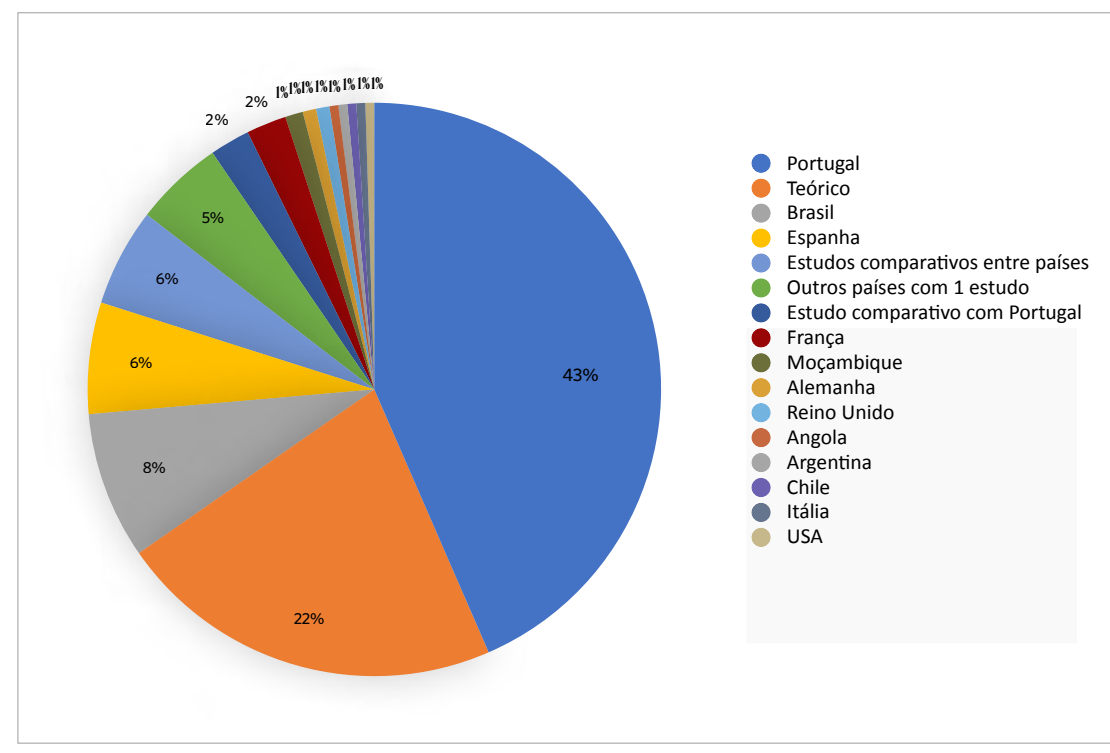

Relativamente à autoria, identificamos diversidade nos artigos das duas revistas. $\mathrm{Na}$ ex æquo, 86\% dos/as autores/as aparecem com um trabalho apenas em todo o histórico das edições e na Faces de Eva, a percentagem é de 92\%. Esses números demonstram como as revistas têm constituído oportunidades para diferentes autoras/es publicarem os seus trabalhos.

A pluralidade verifica-se também em relação às coautorias. Ao observamos a relação entre o número de autoras/es por artigo por períodos das revistas, percebemos como tem sido crescente a presença de trabalhos provenientes de trabalho colaborativo. Verificamos que, na ex æquo (ver gráfico 11), os números com trabalhos assinados por uma pessoa reduziram de 89 no período de 1999 a 2004 para 41 no período mais recente, de 2015 a 2019. Na Faces de Eva (ver gráfico 12), a redução foi ainda mais significativa - de 83 no primeiro período para 35 de 2015 a $2018 .{ }^{9}$

Em nosso entender, esta crescente coautoria tem por base um conjunto de factores. Em primeiro lugar, será resultado da pressão para publicar a que assistimos em todas as áreas científicas e desde que começaram a disseminar-se modelos de desempenho científico assentes em medidas bibliométricas. De algum modo, pode dizer-se que assistimos a um efeito de spill over da cultura de publicação das ciências da vida e da natureza, ou experimentais, se preferirmos, para as restantes

A edição de 2019 ainda não havia sido publicada até à realização desta pesquisa, finalizada em agosto de 2019. 
ciências, não experimentais. Enquanto nestas predominava a autoria isolada, naquelas sempre houve a prática de publicar em coautoria numerosa e diversa em termos das categorias académicas e até de instituições e geografias envolvidas.

\section{Gráfico 10.}

Faces de Eva - Países mais pesquisados

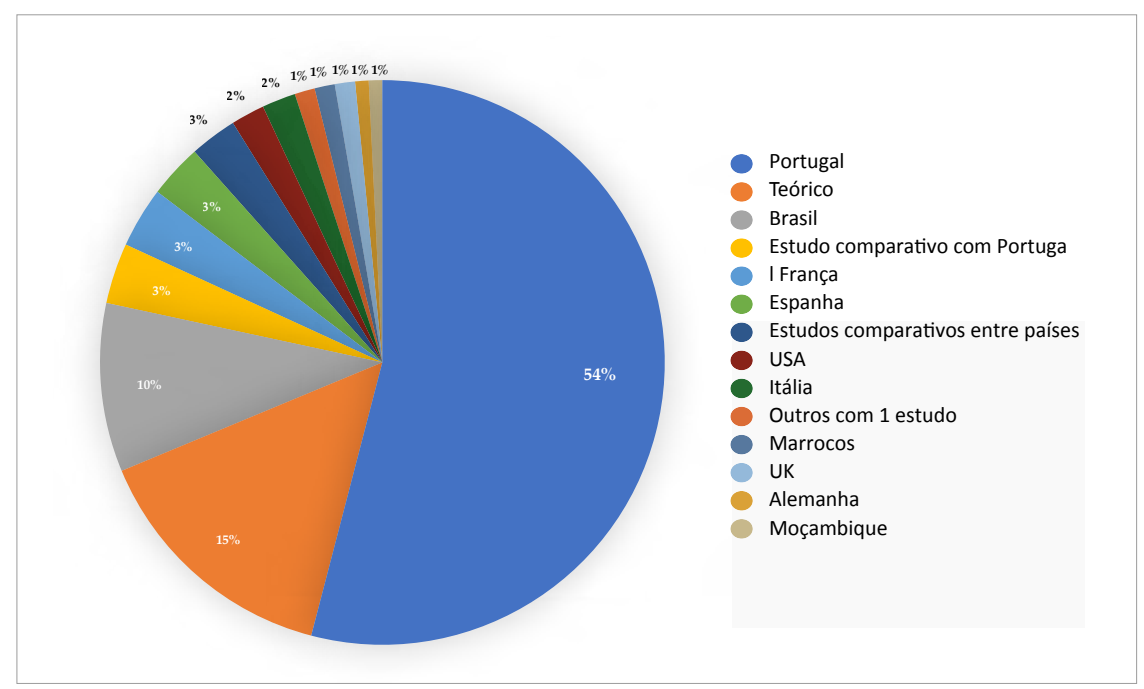

Outro factor explicativo residirá na crescente natureza formal e institucional que preside ao trabalho colaborativo existente neste campo dos EMGF. Daí surgirem cada vez mais textos assinados por orientadoras/es e orientandas/os, elaborados no quadro de dissertações de programas de pós-graduação de mestrado ou doutoramento em EMGF. O que era antes considerada uma colaboração informal (neste campo, como em outros), é agora considerada uma colaboração formal, pela qual as/os orientadoras/es dos trabalhos de investigação esperam, pela coautoria, formalizar a sua contribuição, quando antes esse seu contributo seria muito pouco reconhecido (Henriksen, 2016). Estas coautorias que envolvem orientandas/os e orientadoras/es têm uma natureza hierárquica, mais comum no campo das EMGF, segundo o estudo comparativo de Madison et al. (2018) e avaliado negativamente, uma vez que não decorrem de trabalho colaborativo entre pares.

Esse pode ser, claramente, um indicador de maior institucionalização dos EMGF. Com efeito, por altura do aparecimento das revistas não existia a pressão para publicar artigos enquanto se desenvolvia a pesquisa a submeter em provas de mestrado e doutoramento, nas quais era suposto apresentar trabalho original. Hoje em dia, em muitas universidades é possível defender provas de doutoramento com base em 3 ou 4 artigos publicados, onde nem sempre a pessoa que obtém o grau aparece como primeira autora dos artigos integrados na tese. 
Gráfico 11.

ex æquo - Número de autoras/es por artigo, por quinquénio

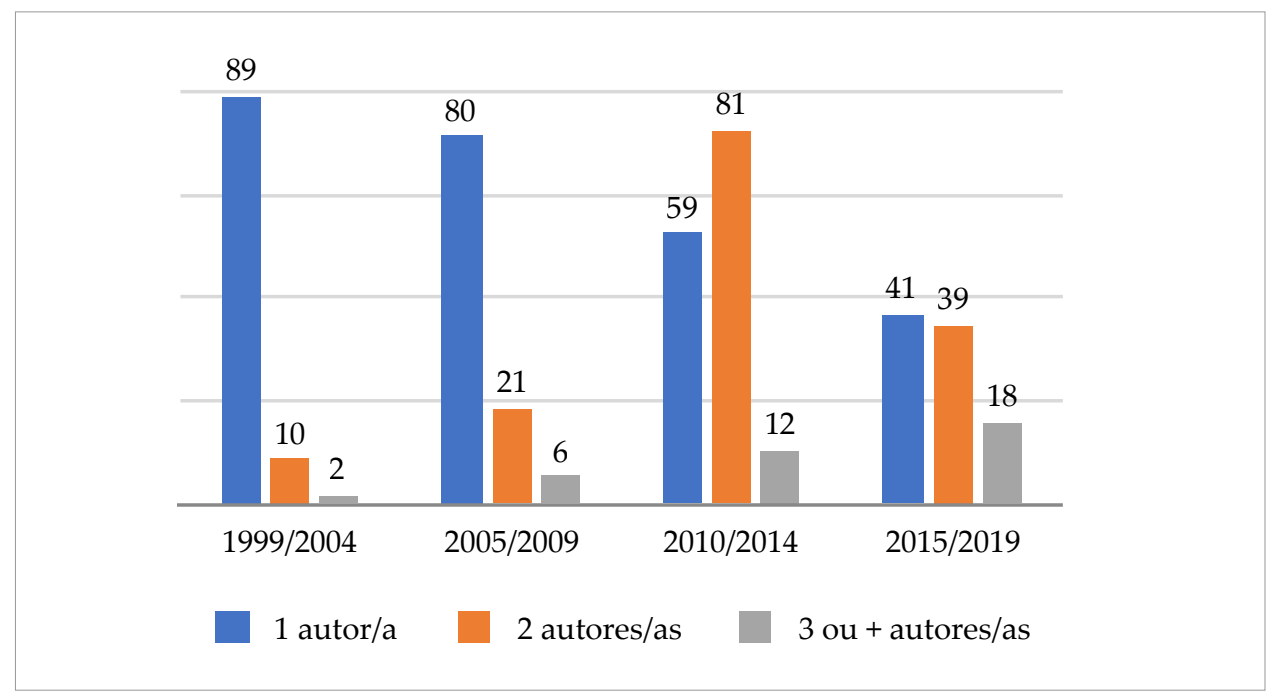

Gráfico 12.

Faces de Eva - Número de autoras/es por artigo, por quinquénio

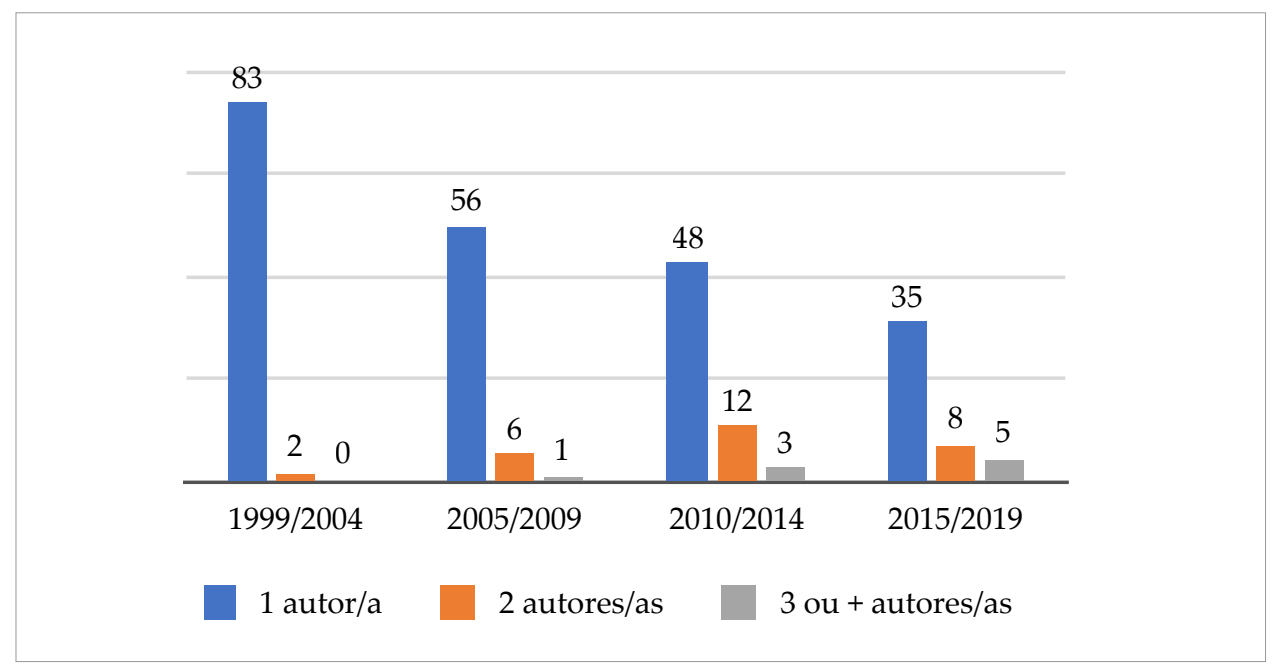

O aumento das coautorias é ainda reflexo da crescente prevalência de projetos financiados que envolvem equipas da mesma área e de estudos provenientes de áreas das ciências sociais que envolvem a participação de investigadoras/es de outros campos do saber que, em geral, exigem uma diversidade de especialidades 
para produzir e analisar quantidades importantes de informação estatística (ou de outra natureza), o que não acontece nas humanidades. Nestas, é mais comum um trabalho mais individual, de recorte teórico, com base sobretudo em metodologias qualitativas (Hoppen \& Vanz 2020, 11). Cumulativamente, começam também a surgir mais frequentemente artigos produzidos nas áreas da saúde (psiquiatria; psicologia; neurociências) que requerem a participação de investigadores/as em EMGF, em virtude da necessária análise interseccional dos temas que fazem parte das respetivas agendas científicas.

A presença de mais textos em coautoria resulta também no aumento da presença feminina nas publicações, dado que $87 \%$ da coautoria, quer na ex æquo, quer na Faces de Eva, é composta por mulheres, apesar desta percentagem representar números absolutos distintos (166 mulheres na ex æquo e 46 na Faces de Eva). A participação masculina na coautoria também apresenta índices idênticos nas revistas $(13 \%)$, mas traduz a presença de 25 coautores na ex æquo e 7 na Faces de Eva.

\section{Recurso à linguagem inclusiva}

Gráfico 13.

ex æquo - Tipo de linguagem utilizada, por quinquénio

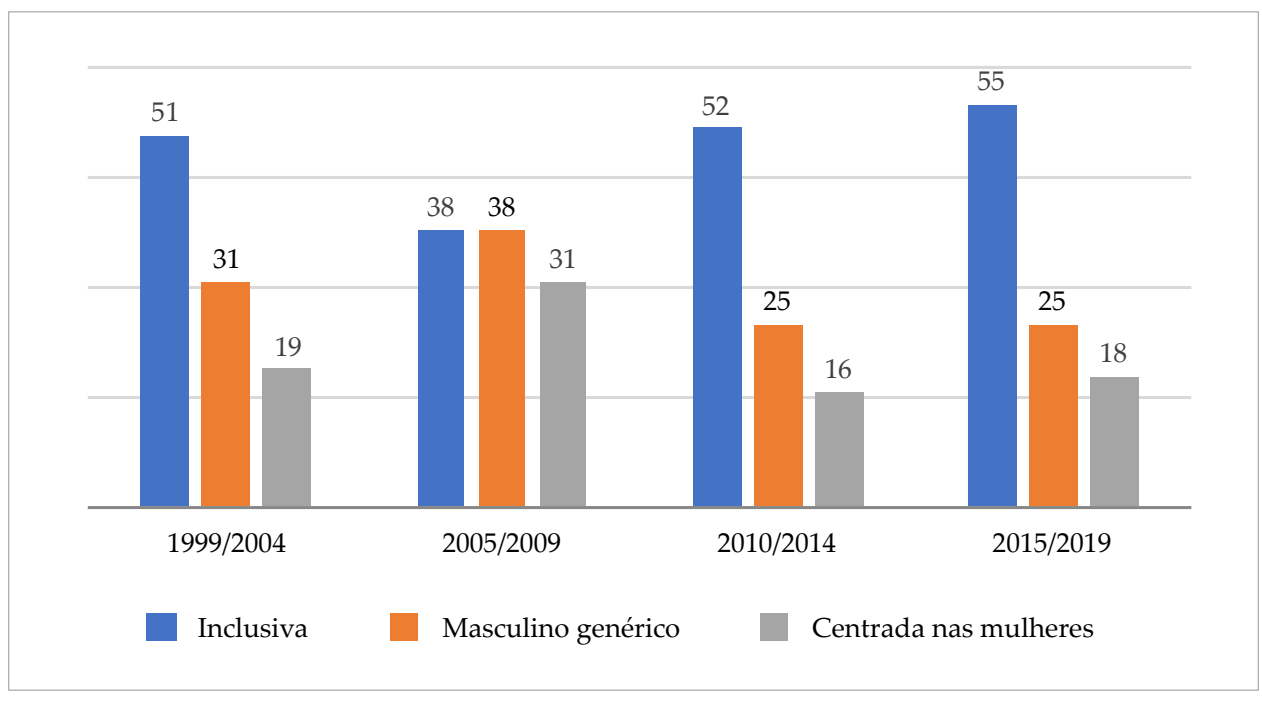

Ao decompor a análise dos dados em períodos de cinco anos, percebemos a preocupação dos/as autores/as e coautores/as com a linguagem adotada na escrita dos trabalhos publicados na ex æquo. Desde as suas primeiras edições, a linguagem inclusiva, ou seja, com a flexão de género evidente como forma de combate ao 
sexismo da linguagem (Abranches 2009), tem sido o estilo maioritário de expressão para autores/as e coautores/as. Na Faces de Eva, a linguagem baseada no masculino genérico apresenta maiores ocorrências em diferentes períodos de sua história, mostrando assim que a problematização da linguagem permanece restrita a poucos/as autores/as.

O registo da linguagem leva-nos a perceber que também os conceitos importantes dos EMGF que são trabalhados se vão alterando ao longo dos 20 anos das revistas, talvez fruto das recomendações internacionais, como as do Conselho da Europa (1990; 2007), sobre a eliminação do sexismo na linguagem, e da importância crescente que as questões da linguagem inclusiva têm assumido nas políticas públicas e nos compromissos transnacionais ratificados por Portugal e outros países (ex: CEDAW).

\section{Gráfico 14.}

Faces de Eva - Tipo de linguagem utilizada, por quinquénio

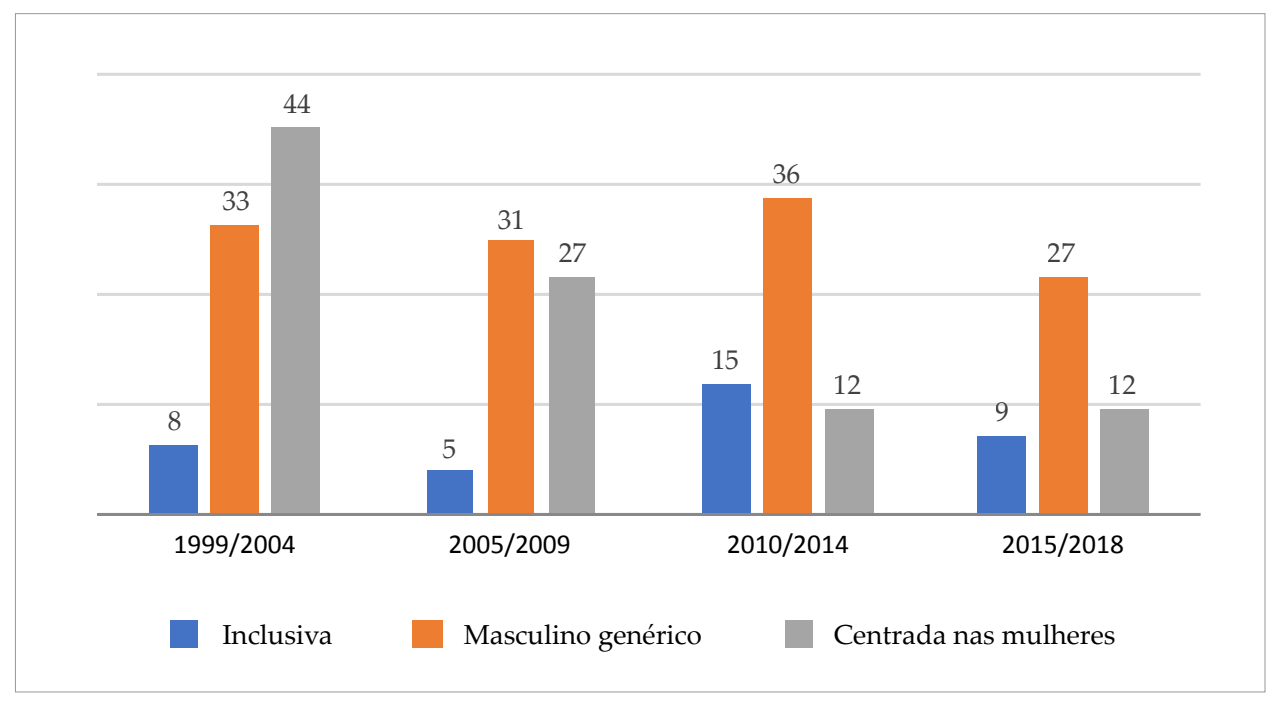

\section{Quadros conceituais e disciplinares prevalecentes}

No caso da ex æquo (ver gráfico 15), fica evidente a expressão crescente de preocupações, posições e reflexões feministas e dos feminismos nos três primeiros períodos da publicação. Apenas no período mais recente, de 2015 a 2019, observamos a redução dos termos «feminismos» e «feministas» nos artigos. Por outro lado, esse movimento decrescente pode estar relacionado com o salto verificado na presença do conceito de género e de termos derivados, como genderizado, que 
passou a aparecer nada menos que 43,64 vezes por trabalho, em média, nas edições publicadas de 2015 a 2019.

A crescente utilização do conceito de género, em alguns casos, estará associada à procura de maior legitimidade científica, uma hipótese aventada em outros estudos produzidos, nomeadamente, sobre o Brasil, como, por exemplo, nos referenciados por Hoppen e Vanz (2020). Não deixa de ser inquietante esta tendência para recorrer ao potencial efeito «branqueador» imputado por algumas abordagens ao conceito de género, enquanto distanciamento de explicações biológicas. De qualquer modo, a inquietação decorre da substituição que é feita - desaparecem os termos feminista e feminismo para sobressair os de género e de LGBTI, enquanto o emprego de masculinidade e de feminilidade praticamente não sofre alterações. Há claramente nesta evolução um acompanhamento das agendas dos movimentos feministas ao longo das duas últimas décadas.

Tendência semelhante foi verificada no crescimento dos trabalhos relacionados com as sexualidades e que abordam, entre outras, as questões decorrentes da crescente visibilidade que as problemáticas suscitadas pelas identidades LGBTI têm suscitado. Entre 1999 e 2004, esses termos apareciam apenas 0,1 vezes, em média, nos artigos. Já nas últimas edições da revista, a média por artigo passou a ser de 7,8 ocorrências.

\section{Gráfico 15.}

ex æquo - Número médio de vezes que os conceitos são usados, por artigo, por quinquénio

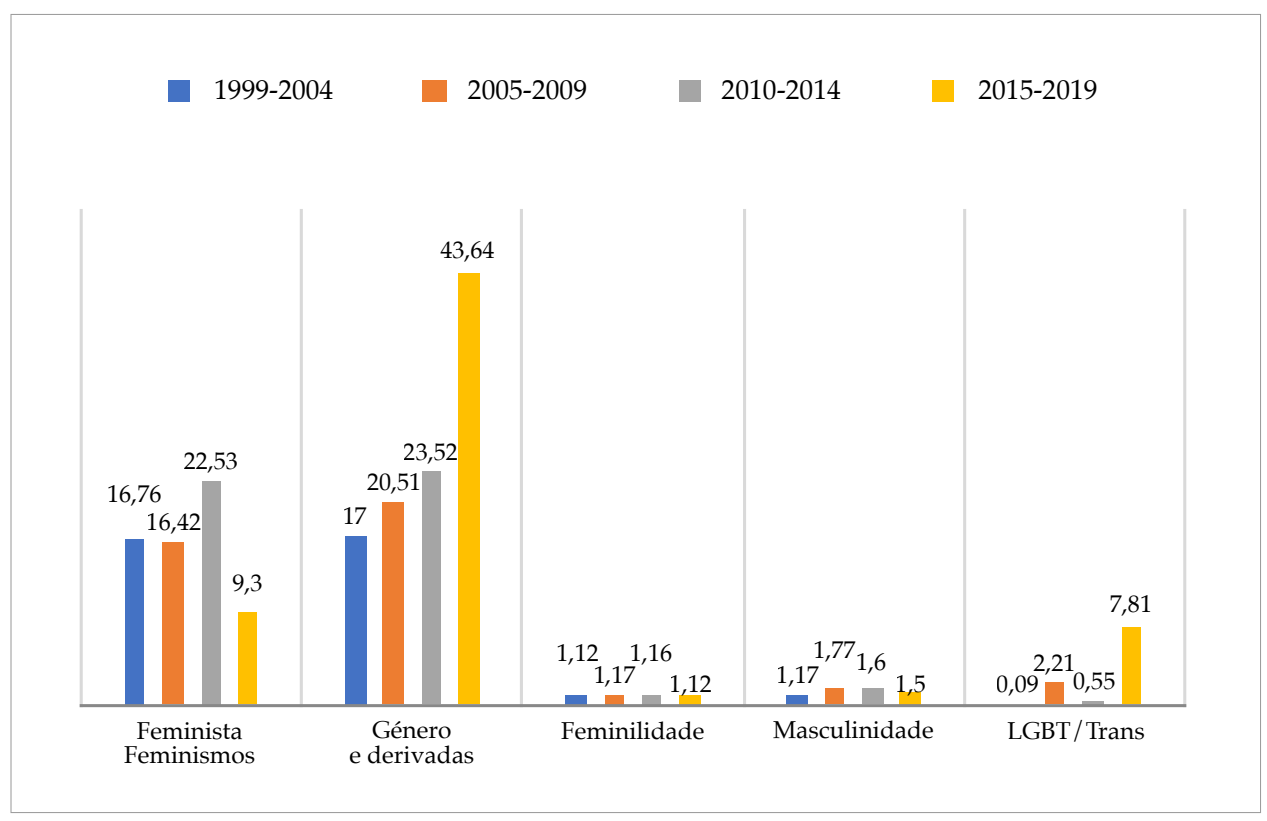


Com relação à Faces de Eva, é importante ressalvar que os dados obtidos durante o levantamento não nos permitem fazer uma análise comparável, pois tivemos acesso à versão digital da revista apenas a partir da $32^{a}$ edição, disponível no endereço da biblioteca eletrónica SCIELO. Dessa maneira, nas primeiras 31 edições, trabalhamos com edições impressas das revistas e, portanto, tivemos de restringir a pesquisa aos títulos, resumos e palavras-chave, sendo que estes últimos também não constavam em todos os trabalhos, pois verificamos que a formatação da revista passou por mudanças ao longo dos seus 20 anos de história e, nas primeiras edições, a formatação não previa resumos e palavras-chave, por exemplo. Essas limitações justificam o escasso número de vezes em que os conceitos são aqui contabilizados e as grandes diferenças entre os dois primeiros quinquénios e os dois últimos.

\section{Gráfico 16.}

Faces de Eva - Número médio de vezes que os conceitos são usados, por artigo, por quinquénio

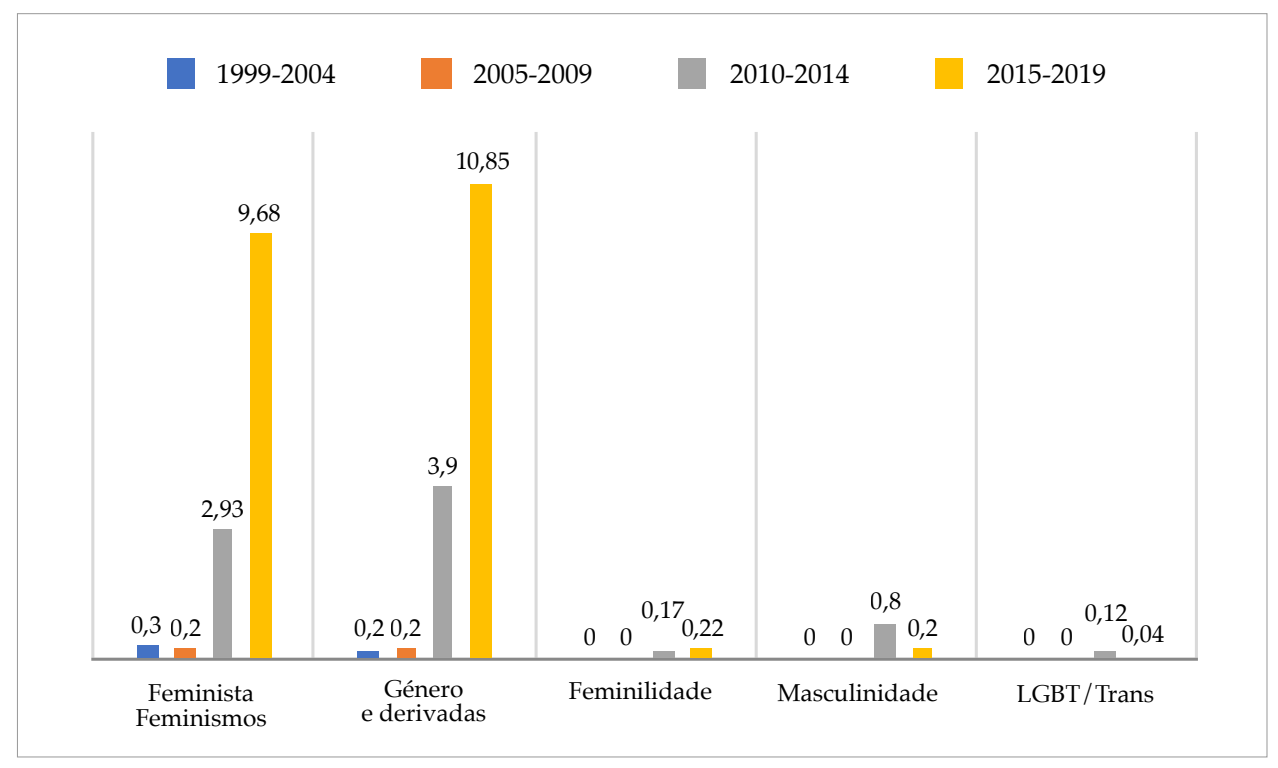

Outra variável obtida no levantamento e aqui analisada por período é a área disciplinar da/o $1^{\circ}$ autor/a. A partir dos dados podemos compreender dois movimentos simultâneos nas revistas: de um lado percebemos a consolidação de áreas enquanto locus de debate para os EMGF, como a Sociologia e as Ciências da Educação na ex æquo (ver gráfico 17) e a História e os Estudos Literários/Linguísticos na Faces de Eva (ver gráfico 18); mas do outro, a análise por períodos expõe o crescente interesse de outras áreas. Neste movimento, observamos os ganhos alcançados pela Psicologia e os Estudos Culturais e da Comunicação na ex æquo e da Sociologia na Faces de Eva. 


\section{Gráfico 17.}

ex æquo - Número de artigos por área disciplinar, por quinquénio

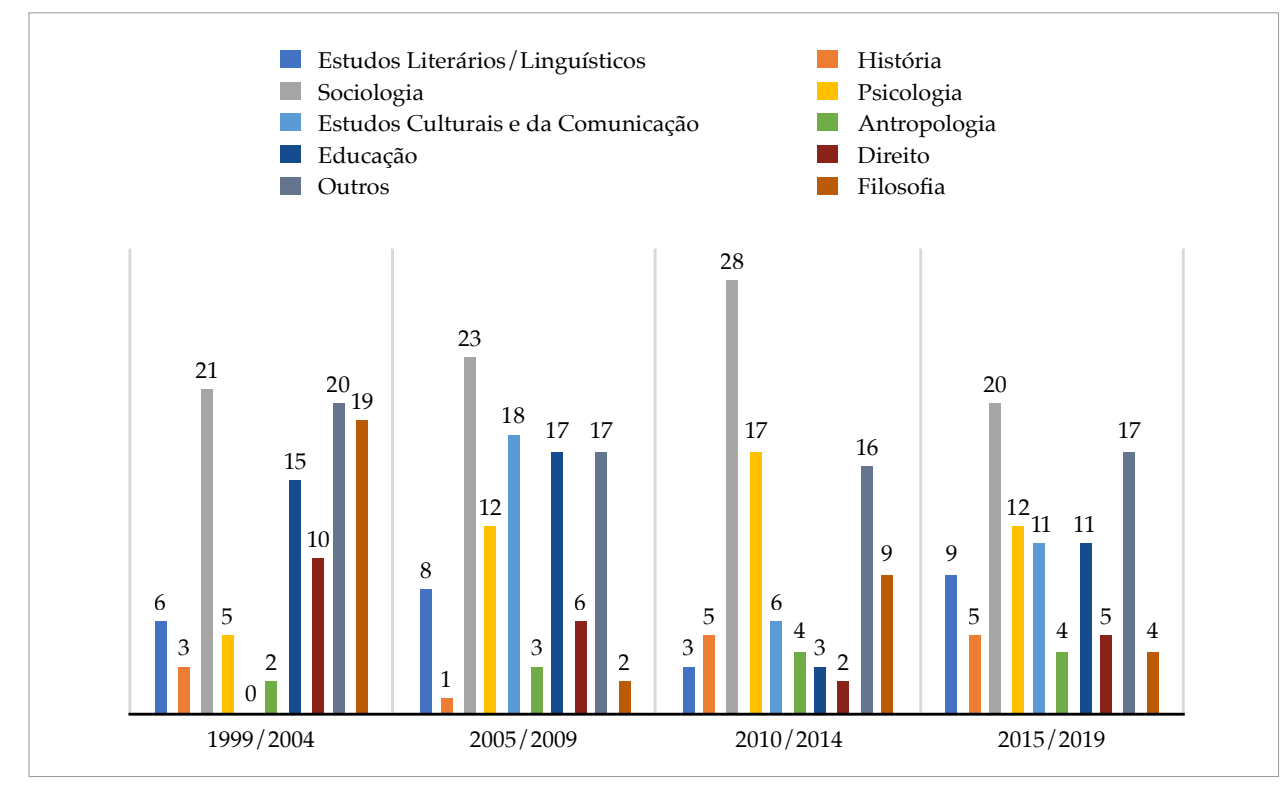

Gráfico 18.

Faces de Eva - Número de artigos por área disciplinar, por quinquénio

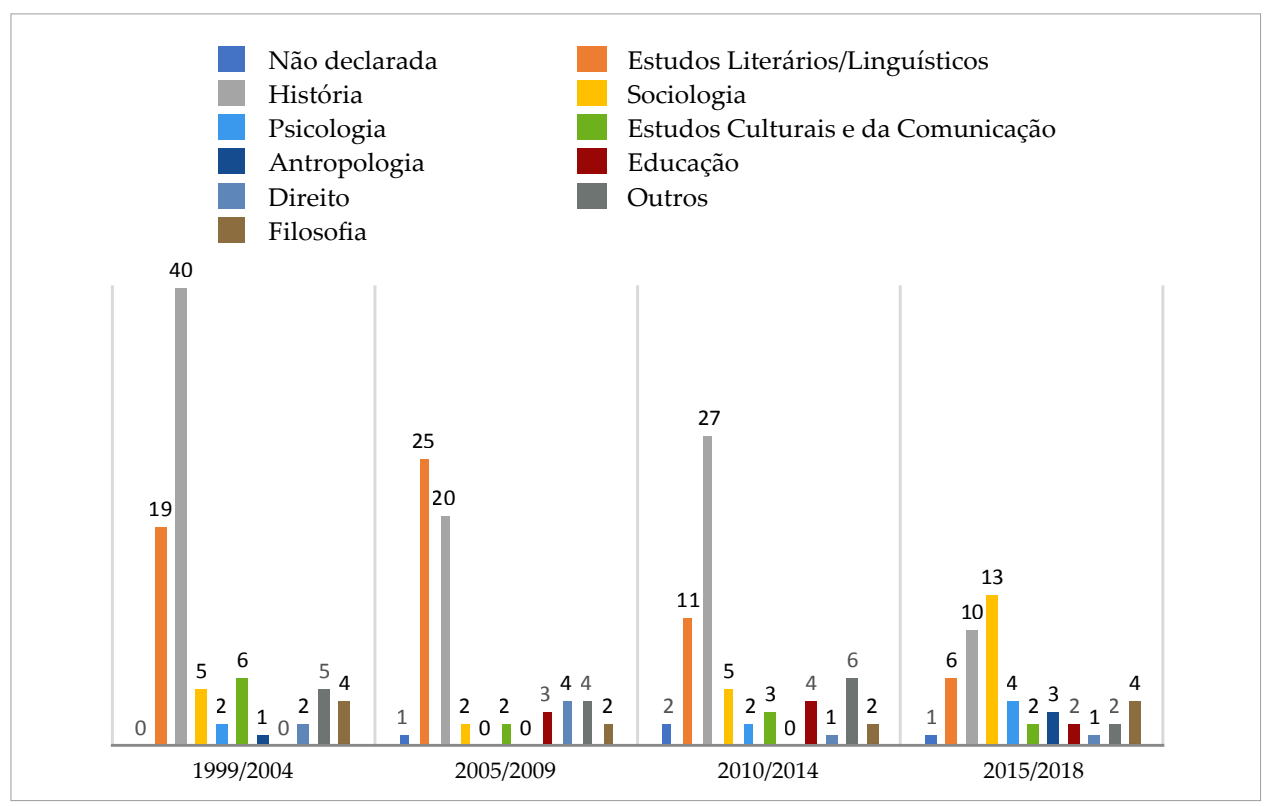


A maior presença de determinadas áreas disciplinares incide diretamente sobre as metodologias mais adotadas nos estudos. Além disso, indica os processos de formulação e consolidação de diferentes perspectivas de trabalho nas Ciências Humanas e Sociais.

\section{Metodologias e temáticas mais frequentes}

Nas duas revistas, a publicação de ensaios (ver gráficos 19 e 20) apresenta números expressivos nos diferentes períodos, mas com relativa redução nas edições mais recentes, sobretudo na ex æquo. Esse dado remete-nos para a constante atualização da reflexão epistemológica nos EMGF, mas também às dificuldades de acesso aos meios materiais e institucionais para que pesquisas de campo nessa área fossem realizadas com maior fôlego nos primeiros cinco anos das publicações. Ao observarmos o crescimento de metodologias mistas, ou seja, realizadas a partir da combinação de métodos quantitativos e qualitativos, verificamos a alteração gradual no cenário da ex æquo onde observamos mais claramente a utilização de diferentes procedimentos metodológicos.

Na Faces de Eva, identificamos, além da forte presença dos ensaios em níveis semelhantes em todos os períodos, como já referimos, pesquisas com metodologia documental e análise literária com picos significativos em diferentes períodos de publicação - análise documental entre 1999-2004 e análise literária entre 2005-2009. Atribuímos a esta especificidade a presença constante de autoras/es da História e dos Estudos Literários/Linguísticos ao longo das edições de Faces de Eva, sendo uma revista mais voltada para essas áreas.

As metodologias qualitativas de produção e análise de dados têm prevalecido nos EMGF e também nas revistas em análise, como é notório nos dois gráficos que se seguem (19 e 20). Para o exame e descrição das informações trabalhadas neste campo usaram-se as expressões encontradas nas publicações, para mencionar as estratégias de investigação explicitadas pelas/os autoras/es, ainda que se saiba que as mesmas não representam categorizações metodológicas mutuamente exclusivas. Além disso, como pode observar-se nos gráficos 19 e 20, ora se indicam designs de investigação (ex: inquéritos; estudos de caso), ora técnicas de recolha de dados (ex: entrevistas), ora ainda técnicas de análise de dados (ex: estatísticas; análise do discurso).

Essa estratégia metodológica tem-lhes acarretado a crítica que, do ponto de vista positivista, tem sido apontado a estas metodologias - acusados de não serem exatamente académicos, excessivamente ideológicos e teóricos, se basearem em metodologias pobres, por fazerem um limitado uso e análise de dados empíricos e centrarem o seu foco em conceitos abstratos como "estruturas sociais" ou por assumirem uma «ordem do poder de género» (Pereira 2012). Esse tipo de conclusões estão enunciadas em, entre outros, o estudo de Madison e Söderlund (2018), 
que, com base na análise de artigos em revistas de EMGF e de outras abordagens, publicadas na Suécia, levou as autoras a decretar que: «gender studies can do better». Estas críticas derivam claramente da natureza contextual da informação produzida por métodos qualitativos, da orientação mais local das pesquisas, do papel central desempenhado por quem conduz as pesquisas e dos desafios da falta de estruturação das técnicas (Bergano e Vieira 2020). São também críticas decorrentes de análises filiadas em paradigmas objetivistas prevalecentes nas ciências experimentais, e que ignoram as diferenças entre os diversos campos científicos, tal como é denunciado no comentário àquele estudo de Nina Lykke (2018). A validade externa não constitui, com efeito, a preocupação central na investigação qualitativa, pois o objetivo principal não é a generalização dos resultados, mas a validade interna. Neste caso, os critérios de qualidade que devem ser seguidos devem atender à credibilidade das conclusões extraídas, à adequação das respostas dadas às questões de investigação formuladas e à legitimidade dos processos metodológicos mobilizados (Vieira 1999). É por isso que, à metodologia bibliométrica, priorizamos o processo de peer review, anónimo de preferência, apesar das limitações de subjetividade, arbitrariedade e morosidade que lhe são apontadas (Aksnes, Langfeldt, \& Wouters 2019).

Gráfico 19.

ex æquo - Metodologias usadas, por quinquénio

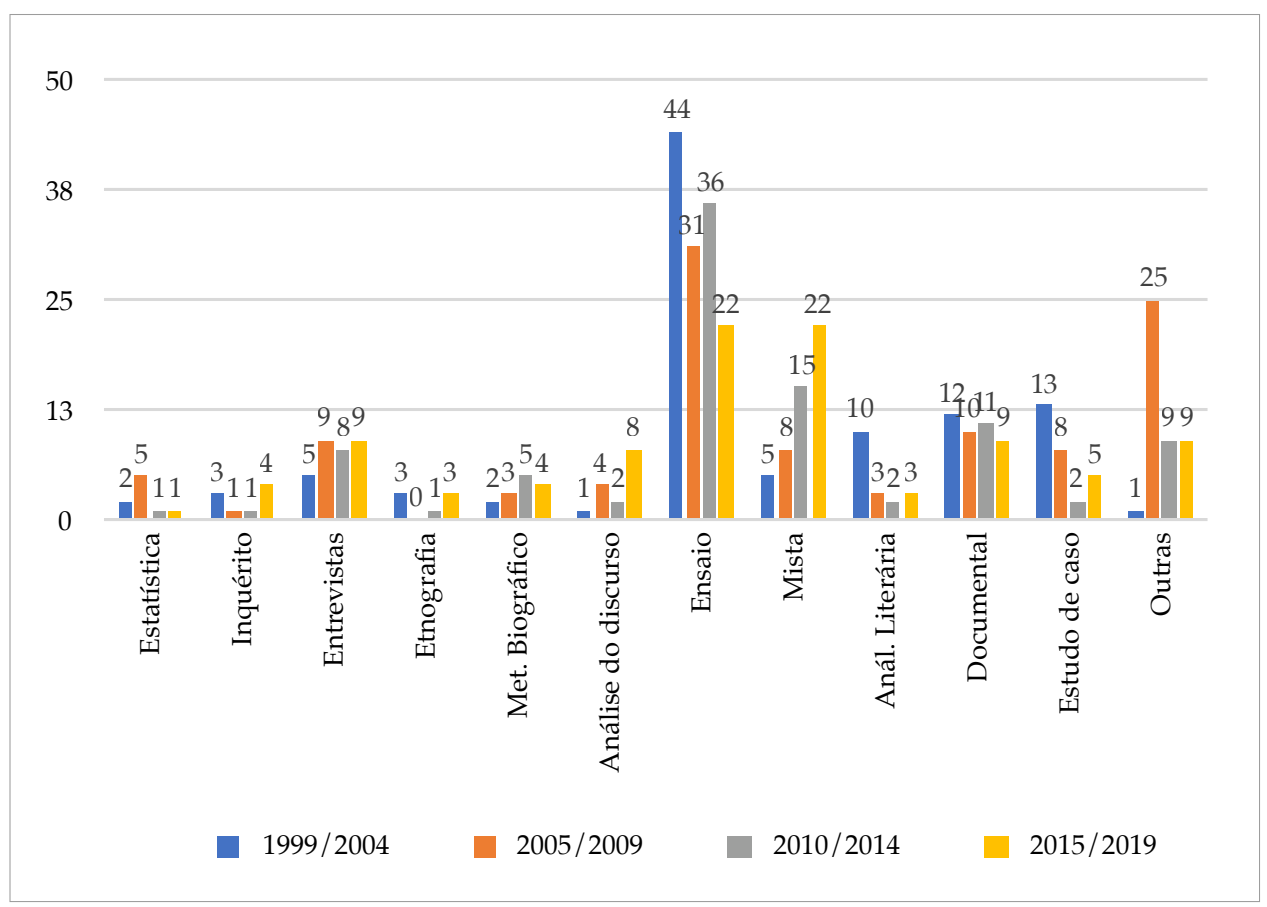


Para além da análise de indicadores quantitativos a partir dos dados recolhidos no corpus documental que serviu de base para este estudo, foi possível fazer uma análise temática dos assuntos tratados na ex æquo. Ficará para outra publicação a exploração dos temas identificados, que foram posteriormente agrupados em categorias conceptuais mais abrangentes..$^{10}$ No gráfico 21 são apresentadas as doze áreas identificadas a partir das palavras-chave escolhidas pelas/os autoras/es dos 399 textos publicados na ex æquo ao longo de duas décadas, divindindo-se a informação por quinquénios.

\section{Gráfico 20.}

Faces de Eva - Metodologias usadas, por quinquénio

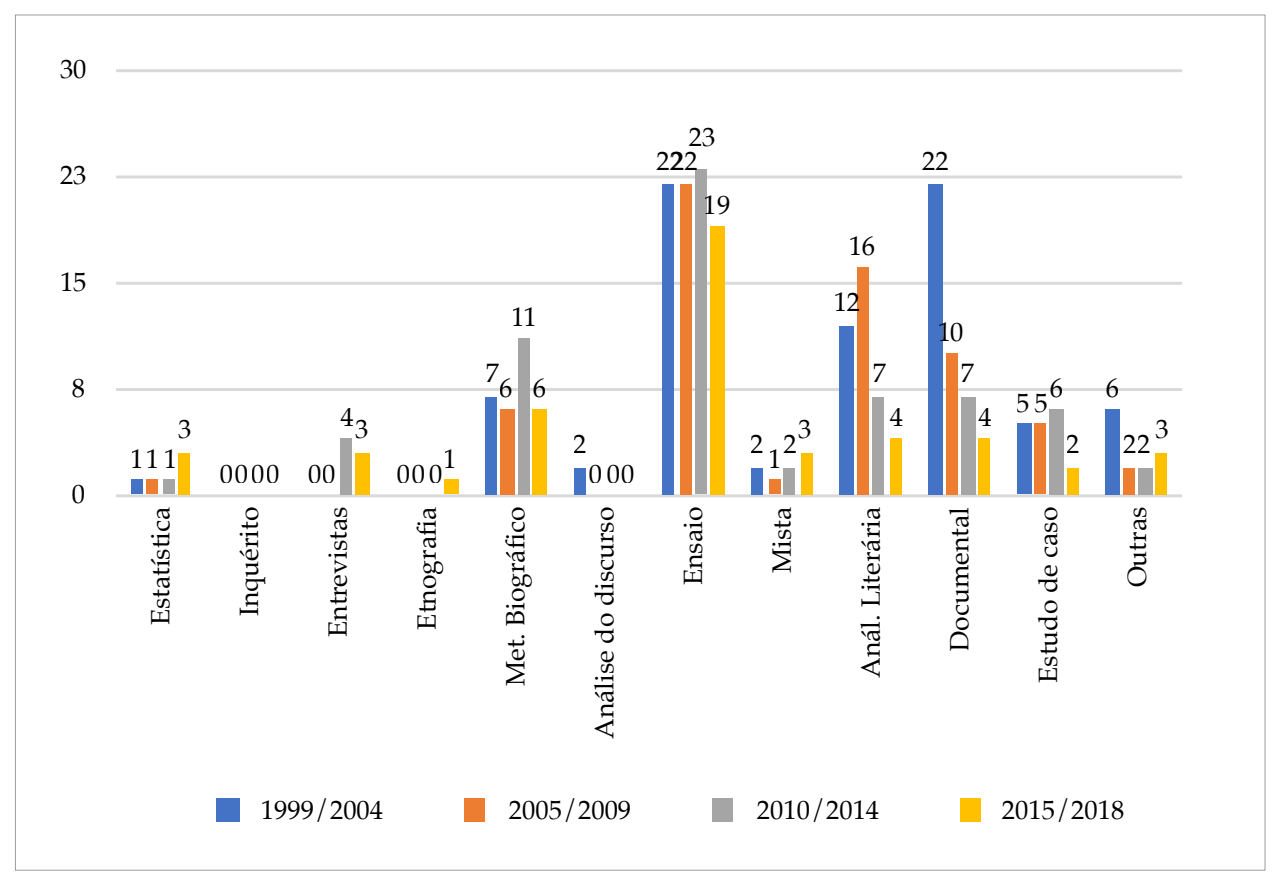

A diversidade de temáticas é assinalável e também aqui as categorias construídas e usadas para a análise da informação não se excluem mutuamente. A indispensável abordagem interseccional de algumas temáticas (ex: violências), a área de proveniência académica/institucional dos/as autores/as e ainda o período de publicação considerado são aspetos que, em nosso entender, não autorizam

A não inclusão da Faces de Eva nesta etapa do trabalho já foi justificada anteriormente, tendo-se devido sobretudo à não disponibilização em formato digital dos primeiros 31 números da revista e às alterações ao nível da formatação que foi sofrendo com os anos. 
uma leitura linear dos dados. É possível que a escolha das palavras-chave tenha sido influenciada por fatores ligados a tendências de mainstreaming em cada época, bem como pelo foco teórico-analítico a partir do qual os temas foram abordados. Também nos parece provável que a visibilidade de uns temas em relação a outros, em casa período considerado, não tenha sido independente das áreas científicas das pessoas que dirigiam as revistas, o que poderá ter-se refletido nas opções relativas à proposta de dossiês temáticos, às redes de cooperação científica que facilitaram certamente a preparação de submissões para publicação, entre outras potenciais questões que abordaremos em trabalhos posteriores decorrentes deste estudo bibliométrico.

\section{Gráfico 21.}

ex aequo - Áreas temáticas identificadas através dos resumos e palavras-chave, por quinquénio

30

23
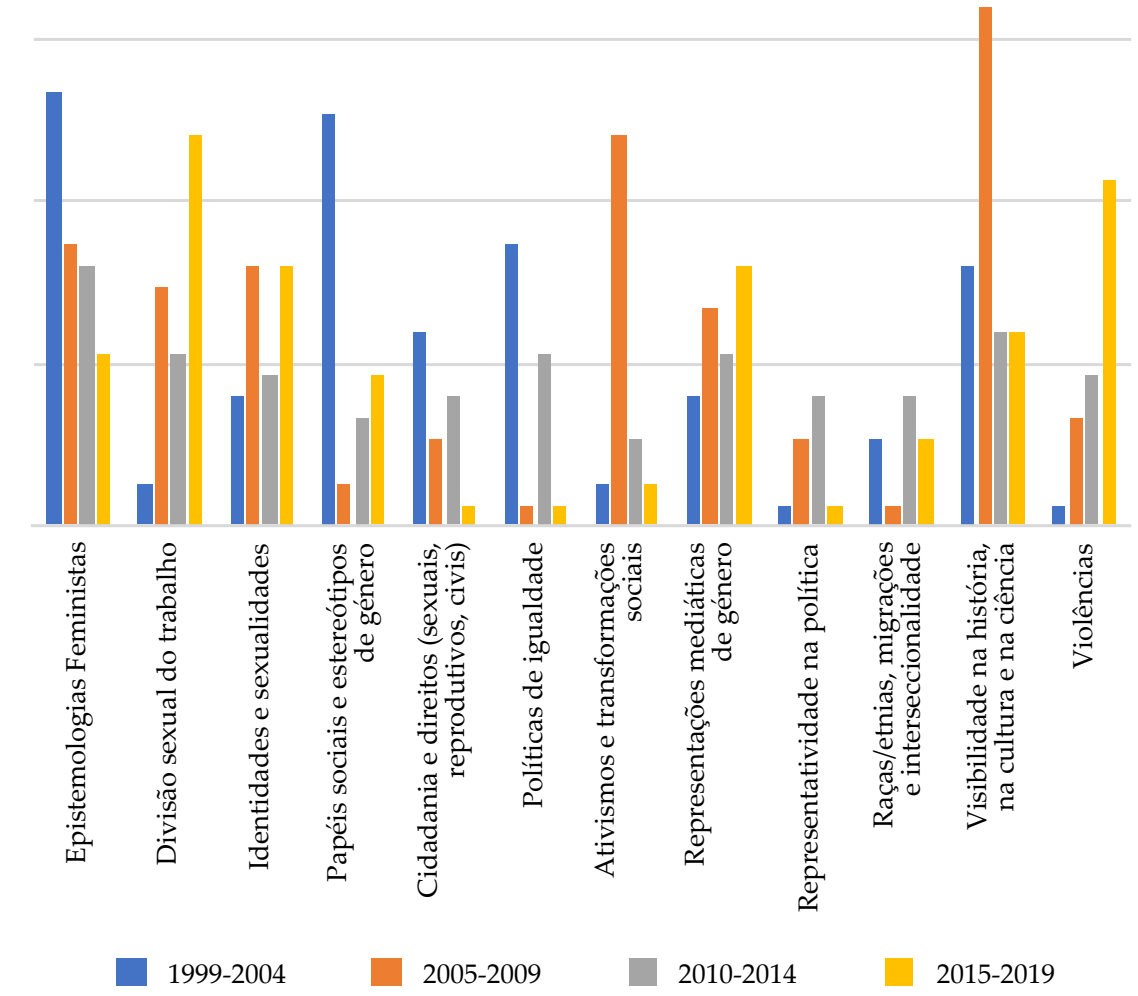


\section{Considerações finais}

O uso da bibliometria e da cientografia para avaliar o desempenho do trabalho científico e das publicações que o veiculam tem aumentado nas últimas décadas. A abordagem quantitativa tem sido objeto de várias críticas, como já foi sublinhado, considerando-se que ela não pode em caso algum substituir a arbitragem por pares. Privilegiando esta modalidade de avaliação, a arbitragem cega por pares, não quisemos deixar de fazer este exercício bibliométrico, como exercício complementar.

É importante enquadrar os dados apurados sobre as duas revistas no contexto dos EMGF, aos quais os estudos bibliométricos mais ou menos têm apontado as seguintes características: revistas com baixo factor de impacto que publicam artigos com poucas citações (Madison e Söderlund 2018, 1163). Seguimos, no entanto, aqui um importante princípio incluído no Leiden Manifesto (Hicks et al. April 2015) - não confundir o factor de impacto de uma revista com a sua qualidade científica. Enquanto noção multidimensional, a qualidade científica passa por critérios como a consistência, a originalidade e o valor social do conhecimento que produz, não podendo por isso ser captada por um único indicador quantitativo, ainda que composto.

O recurso a critérios cientométricos procura informar a tomada de decisão editorial para melhorar a qualidade das revistas, e respetiva promoção e internacionalização, a fim de reforçar o seu posicionamento no panorama editoral e no sistema científico dos EMGF. Neste caso, sendo esta a primeira publicação de outras que se seguirão, procurou-se sobretudo identificar as linhas mais marcantes no desenvolvimento desta área de estudos em Portugal e os caminhos que as suas duas únicas revistas que procuram afirmar-se neste campo têm percorrido.

\section{Agradecimentos}

Estudo financiado pela Comissão para a Cidadania e Igualdade de Género, através da sua medida de Apoio do Estado às ONGM, ao abrigo do Decreto-lei n. ${ }^{\circ}$ 246/98, de 11 de Agosto, alterado pela Lei n. ${ }^{o}$ 37/99, de 29 de Maio.

\section{Referências bibliográficas}

Giovanni Abramo, Ciriaco Andrea D’Angelo, and Alessandro Caprasecca. 2009. «Gender differences in research productivity: A bibliometric analysis of the Italian academic system». Scientometrics, 79(3), 517-539.

Abranches, Graça. 2009. Guia para uma linguagem promotora da igualdade entre mulheres e homens na administração pública. Lisboa: Comissão para a Cidadania e a Igualdade de Género.

Aksnes, Dag W., Liv Langfeldt, e Paul Wouters. 2019. «Citations, Citation Indicators, and Research Quality: An Overview of Basic Concepts and Theories». SAGE Open, 1-17. 
Amâncio, Lígia, e João Manuel de Oliveira. 2014. «Ambivalências e desenvolvimentos dos estudos de género em Portugal». Faces de Eva 32, 23-42.

Barroso, Margarida, Magda Nico, e Elisabete Rodrigues. 2009. «O lugar do género, dos homens e das mulheres na sociologia portuguesa: uma análise a partir da Associação Portuguesa de Sociologia e seus congressos». CIES e-Working Papers 64.

Bergano, Sofia, e Cristina C. Vieira. 2020. Do pessoal ao político: as metodologias de investigação qualitativa como aliadas da ação. ex æquo 41, 15-25. DOI: https:/ / doi.org / 10.22 355/ exaequo.2020.41.01

Borrego, Ángel, Maite Barrios, Anna Villarroya, and Candela Ollé. 2009. «Scientific output and impact of postdoctoral scientists: A gender perspective». Scientometrics, 83(1), 83-101.

Brilhante, Aline Veras Morais, Gracyelle Alves Remigio Moreira, Luiza Jane Eyre de Souza Vieira, and Maria Fontenelle Catribe. 2016. «A bibliometric study on gender violence». Saúde e Sociedade, 25(3), 703-715.

Conselho da Europa. 1990. Recomendação n. ${ }^{\circ}$ R (90) 4 do Comité de Ministros aos Estados-membros sobre a eliminação do sexismo na linguagem, adoptada pelo Comité de Ministros a 21 de fevereiro de 1990.

Conselho da Europa. 2007. Recomendação Rec (2007) 17 do Comité de Ministros aos Estados-Membros sobre Normas e Mecanismos para a Igualdade de Género, adotada pelo Comité de Ministros a 21 de novembro de 2007.

Cronin, Blaise. 1984. The citation process. The role and significance of citations in scientific communication. London: Taylor Graham.

Cronin, Blaise, Anna Martinson, and Elisabeth Davenport. 1997. «Women's studies: Bibliometric and content analysis of the formative years». Journal of Documentation, 53(2), 123-138.

Dehdarirad, Tahereh, Anna Villarroya, and Maite Barrios. 2015. «Research on women in science and higher education: A bibliometric analysis». Scientometrics, 103(3), 795-812.

Feldman, Zeena, and Marisol Sandoval. 2018. «Metric Power and the Academic Self: Neoliberalism, Knowledge and Resistance in the British University». tripleC 16(1): 214-233.

Ferreira, Virgínia. 2001. «Estudos sobre as Mulheres: A construção de um novo campo científico», ex æquo 5, 9-25.

Henriksen, Dorte. 2016. «The rise in co-authorship in the social sciences (1980-2013)». Scientometrics, 107(2), 455-476.

Hicks, Diane, Paul Wouters, Ludo Waltman, Sarah de Rijcke, and Ismael Rafols. April 2015. «The Leiden Manifesto for research metrics». Nature Vol 520, 429-431.

Hoppen, Natascha Helena Franz, and Samile Andréa de Souza Vanz. 2020. «What are gender studies: characterization of scientific output self-named gender studies in a multidisciplinary and international database». Encontros Bibli: revista eletrônica de biblioteconomia e ciência da informação 25, 01-30. DOI: https: / / doi.org/10.5007/1518-2924.2020. e71677

Joaquim, Teresa. 2004. «ex-æquo: Contributo Decisivo para um Campo de Estudos em Portugal». Estudos Feministas 12(N.E.) 264, 88-93.

Lykke, Nina. 2018. «Can't bibliometric analysts do better? How quality assessment without field expertise does not work». Scientometrics 117: 655-666. https:/ / doi.org/10.1007/ s11192-018-2872-x(

Madison, Guy, \& Therese Söderlund. 2018. «Comparisons of content and scientific quality indicators across peer-reviewed journal articles with more or less gender perspective: gender studies can do better». Scientometrics 115,1161-1183. 
McDermott, Patrice. 1994. Politics and scholarship: feminist academic journals and the production of knowledge. Urbana: University of Illinois Press.

Nunes de Almeida, Ana. 1986. «As mulheres e as ciências sociais - os sujeitos e os objetos de investigação«. Análise Social XXII (94), 979-985.

Pereira, Maria do Mar. 2012. «'Feminist theory is proper knowledge, but...': The status of feminist scholarship in the academy». Feminist Theory 13, 283-303.

Pesole, Betta. 2012. «The Feminist 'Successor Science Project' as a Transnational Epistemological Community», e-cadernos CES 18. Disponível em: http:/ / journals.openedition. org/ eces/1509. DOI: https: / / doi.org/10.4000/ eces.1509

Pinto, Teresa. 2009. «ex æquo - 10 anos em revista». ex æquo 19, 63-68.

Reason, Peter. 1994. «Participation in the Evolution of Consciousness.» In Participation in Human Inquiry, editado por Peter Reason, 16-29. London, Sage Publications.

Santos, Raimundo Nonato Macedo dos, e Nair Yumiko Kobashi. 2009. «Bibliometria, Cientometria, Infometria: Conceitos e Aplicações. Tendências da Pesquisa Brasileira em Ciência da Informação». Pesquisa Brasileira em Ciência da Informação e Biblioteconomia 2(1), 155-172.

Söderlund, Therese, \& Guy Madison. 2015. «Characteristics of gender studies publications: A bibliometric analysis based on a Swedish population database». Scientometrics, 105(3), 1347-1387.

Smith, Dorothy. 1987. Women's Perspective as a Radical Critique of Sociology. In Feminism and Social Theory, editado por S. Harding. Milton Keynes: Open University Press, 84-96.

Tsay, Ming-yueh, \& Chia-ning Li. 2017. «Bibliometric analysis of the journal literature on women's studies». Scientometrics, 113(2), 705-734.

Vieira, Ana Sara, Ana Júlia Coelho, Ana Sofia Miquelino, e Pedro Calado. 2016. «Faces de Eva - Um análise bibliométrica». Faces de Eva 36, 34-60.

Vieira, Cristina Maria. 1999. «A Credibilidade da investigação Científica de Natureza Qualitativa: questões relativas à Fidelidade e Validade». Revista Portuguesa de Pedagogia XXXIII(2), 89-101.

Yun, Bitnari; June Young Lee, and Sejung Ahn. 2020. «The Intellectual Structure of Women's Studies: A Bibliometric Study of its Research Topics and Influential Publications». Asian Women, 36(2), 1-23. 


\section{Anexo}

\section{Indicadores bibliométricos}

1) Número da revista ex æquo

2) Ano

3) Título do artigo

4) Nome de $1^{\circ}$ autor/a

5) Sexo da/o 1. ${ }^{\text {ao }}$ autor/a: Fem $=1$; Masc $=2$

6) Nome de 2. ${ }^{\circ}$ autor/a

7) Nome de $3 .^{\circ}$ autor/a

8) Nome de $4 .{ }^{\circ}$ autor/a

9) Nome de 5. ${ }^{\circ}$ autor/a

10) Autoria (de 0 a n)

11) Número de pessoas coautoras do sexo feminino (de 0 a n)

12) Número de pessoas coautoras do sexo masculino (de 0 a n)

13) Língua do artigo (Português $=1$; Inglês $=2$; Espanhol $=3$; Francês $=4$ )

14) País da instituição de filiação da/o $1 .^{\circ}$ autor/a

15) País da instituição de filiação da/o $2{ }^{\circ}$ autor/a

16) Instituição de filiação de $1 .^{\circ}$ autor/a (Universidade $=1$; Instituição pública $=2$; Outra $=3$ )

17) Instituição especializada em Género: $\operatorname{Sim}=1 ;$ Não $=2$.

18) Área disciplinar de 1 . $^{\circ}$ autor/a - Estudos Literários/Linguísticos $=1$; História $=2$; Sociologia $=3$; Psicologia $=4 ;$ Estudos Culturais e da Comunicação $=5$; Antropologia $=6 ;$ C. da Educação $=7 ;$ Direito $=8 ;$ Outras $=9 ;$ Filosofia $=10$

19) Tópico central do artigo

20) e-mail de todos/as os/as autores/as

21) Palavras-chave em Português 1

22) Palavras-chave em Português 2

23) Palavras-chave em Português 3

24) Palavras-chave em Português 4

25) Palavras-chave em Português 5

26) Palavras-chave em inglês 1

27) Palavras-chave em inglês 2

28) Palavras-chave em inglês 3

29) Palavras-chave em inglês 4 
30) Palavras-chave em inglês 5

31) Texto original $(=1)$ ou traduzido $(=2)$

32) País sobre o qual incide o estudo

33) Metodologia Quantitativa (estatísticas =1; inquérito = 2); Qualitativa (entrevistas = 3; etnografia $=4$; mét biográfico $=5$; análise do discurso $=6$ ); Ensaio $=7$; Entrevista a Mulheres importantes (caso das Faces de Eva) = 8; Análise de redes $=9$; Mista $=10$, Análise Literária $=11$; Documental $=12$; Estudo de caso $=13 ;$ Outras $=14$.

34) Usa palavra feminista/s (ou feminismo/s) de 0 a $n$ vezes

35) Usa a palavra género (ou derivadas) de $0 \mathrm{n}$ vezes

36) Usa linguagem inclusiva $=1$; masculino genérico $=2$

37) Número de obras citadas no total

38) Número de livros citados no artigo (de 0 a n)

39) Número de artigos em revistas citados no artigo (de 0 a n)

40) Número de outro tipo de publicações citados no artigo (relatórios; blogs; working papers) (de 0 a $n$ )

41) País mais frequente nas referências bibliográficas incluídas no artigo. 
Virgínia Ferreira. Professora Associada da Faculdade de Economia da Universidade de Coimbra (FEUC); Investigadora do Centro de Estudos Sociais (CES). Socióloga, com interesses de pesquisa sobre as desigualdades no mercado de trabalho, exclusão social, equilíbrio trabalho/vida familiar e políticas de igualdade sexual. Membro fundador da Associação Portuguesa de Estudos sobre as Mulheres. Tem publicado em revistas e coletâneas nacionais e internacionais.

Endereço eletrónico: virginia@fe.uc.pt

Cristina C. Vieira. Professora Associada da Faculdade de Psicologia e de Ciências da Educação da Universidade de Coimbra. Membro integrado do Centro de Investigação em Educação de Adultos e Intervenção Comunitária (CEAD) da Universidade do Algarve CEAD - apoiado por Fundos Nacionais através da FCT, no âmbito do Projeto UIDB/05739/2020. Ampla experiência de docência universitária na área das metodologias quantitativas e qualitativas de investigação em ciências sociais e humanas. Coautora dos cinco Guiões de Educação Género e Cidadania publicados pela CIG.

Endereço eletrónico: vieira@fpce.uc.pt

Maria João Silveirinha. Professora Associada da Faculdade da Universidade de Coimbra. Membro integrado do Centro de Investigação ICNova - Instituto da Comunicação da Nova. Docência universitária e investigação na área das Ciências da Comunicação, com particular interesse no cruzamento destas com as questões de género na comunicação e nos media.

Endereço eletrónico: mjsilveirinha@gmail.com

Elizângela Carvalho. Estudante de Doutoramento em Ciências da Comunicação na Universidade de Coimbra, bolseira FCT e associada ao Centro de Investigação ICNova. Na sua investigação doutoral, procura investigar o espaço destinado às mulheres no/a partir do jornalismo.

Endereço eletrónico: elizc.noronha@gmail.com

Priscila Freire. Estudante de Doutoramento em Sociologia na Universidade de Coimbra. Docente da Escola Superior Normal da Universidade do Estado do Amazonas (UEA), Manaus, Brasil. A sua tese de doutoramento incide sobre «Educação sensível ao gênero? Uma análise pós-estruturalista da política de educação do Brasil».

Endereço eletrónico: priscillafreyre@hotmail.com 